\title{
Tetraspanins Function as Regulators of Cellular Signaling
}

\author{
Christina M. Termini and Jennifer M. Gillette * \\ Department of Pathology, University of New Mexico Health Sciences Center, Albuquerque, NM, USA
}

Tetraspanins are molecular scaffolds that distribute proteins into highly organized microdomains consisting of adhesion, signaling, and adaptor proteins. Many reports have identified interactions between tetraspanins and signaling molecules, finding unique downstream cellular consequences. In this review, we will explore these interactions as well as the specific cellular responses to signal activation, focusing on tetraspanin regulation of adhesion-mediated (integrins/FAK), receptor-mediated (EGFR, TNF- $\alpha$, c-Met, c-Kit), and intracellular signaling (PKC, PI4K, $\beta$-catenin). Additionally, we will summarize our current understanding for how tetraspanin post-translational modifications (palmitoylation, N-linked glycosylation, and ubiquitination) can regulate signal propagation. Many of the studies outlined in this review suggest that tetraspanins offer a potential therapeutic target to modulate aberrant signal transduction pathways that directly impact a host of cellular behaviors and disease states.

\section{OPEN ACCESS}

Edited by:

David Holowka,

Cornell University, USA

Reviewed by:

Glenn Cruse,

North Carolina State University, USA

Martin E. Hemler,

Dana-Farber Cancer Institute, USA

*Correspondence:

Jennifer M. Gillette

jgillette@salud.unm.edu

Specialty section:

This article was submitted to Membrane Physiology and Membrane

Biophysics,

a section of the journal Frontiers in Cell and Developmental

Biology

Received: 14 November 2016 Accepted: 22 March 2017 Published: 06 April 2017

Citation:

Termini CM and Gillette JM (2017)

Tetraspanins Function as Regulators of Cellular Signaling.

Front. Cell Dev. Biol. 5:34.

doi: 10.3389/fcell.2017.00034
Keywords: tetraspanins, signal transduction, tetraspanin-enriched microdomains, adhesion-mediated signaling, receptor-mediated signal transduction

\section{INTRODUCTION}

Tetraspanins are membrane-spanning proteins with a conserved structure that function primarily as membrane protein organizers. Phylogenetic analysis identified 33 tetraspanins in humans, 37 in Drosophila melanogaster (Charrin et al., 2014), and 20 in Caenorhabditis elegans (Huang et al., 2005), while only 17 were identified in Arabidopsis thaliana (Boavida et al., 2013). Tetraspanins have also been identified in the ameoba, Dictyostelium discoideum, which exists as both a unicellular and multicellular organism (Albers et al., 2016). While some tetraspanins are expressed ubiquitously in humans, others are cell or tissue specific (Maecker et al., 1997; de Winde et al., 2015), providing a means to regulate the signal transduction associated with a breadth of cellular processes.

Members of the tetraspanin family of proteins have four transmembrane domains, which contribute to the creation of a small (EC1) and large (EC2) extracellular loop (Figure 1). The large extracellular loop contains a conserved Cys-Cys-Gly amino acid motif (CCGmotif), as well as two other conserved cysteine residues. EC2 of CD81 was resolved using crystallography (Kitadokoro et al., 2001), where the authors demonstrated that the four conserved cysteine resides within EC2 promote the formation of disulfide bridges, as had been suggested by previous reports (Levy et al., 1991; Tomlinson et al., 1993; Maecker et al., 1997). Moreover, molecular modeling studies using the CD81 EC2 structure as a template predicted the topography of several other tetraspanins including CD37, CD53, CD82, and CD151 (Seigneuret et al., 2001; Seigneuret, 2006). These studies demonstrated that the EC2 domain of tetraspanins consist of one conserved and one variable domain, with the conserved domain consisting of a three-helix bundle while the variable domain is unique to particular tetraspanins. A recent report resolved a crystal structure of full-length CD81, finding that the four transmembrane domains create a cholesterol-binding pocket (Zimmerman et al., 2016). 


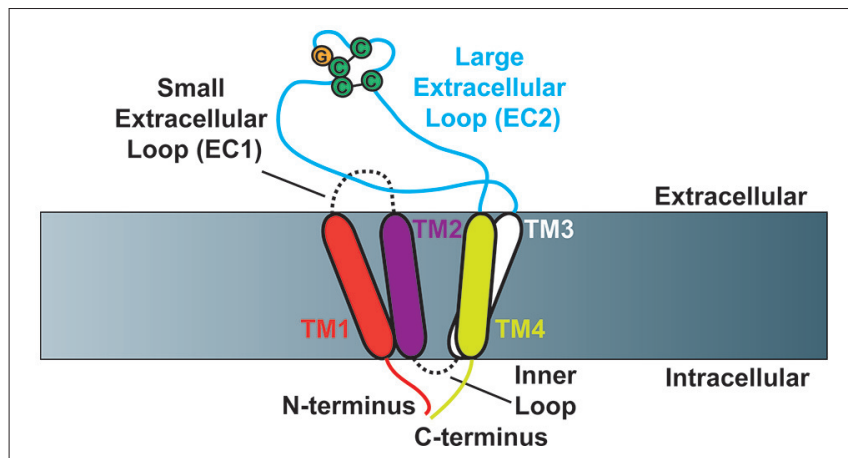

FIGURE 1 | Schematic of tetraspanin molecular structure (Based on Zimmerman et al., 2016). Cartoon depicting the structural characteristics of tetraspanins. Tetraspanins have four transmembrane domains (TM1-TM4), which create one small (EC1) and one large (EC2) extracellular loop as well as a short inner loop. The $\mathrm{N}$ - and $\mathrm{C}$-termini of tetraspanins are localized to the intracellular side of the membrane. The Cys-Cys-Gly amino acid motif is depicted in addition to the two characteristic disulfide bonds that are formed in EC2.

Furthermore, the authors performed molecular dynamics simulations that suggest CD81 can adopt an open or closed conformation depending on whether or not cholesterol is bound.

In addition to the defining features of tetraspanins, many members of the tetraspanin family also contain post-translational modifications. For example, tetraspanins may be palmitoylated at membrane proximal cysteine residues, which was demonstrated to regulate protein-protein interactions (Berditchevski et al., 2002; Charrin et al., 2002; Yang et al., 2002, 2004). Meanwhile, tetraspanins can also be $\mathrm{N}$-linked glycosylated at asparagine residues, which is less clearly understood (Ono et al., 1999; Stuck et al., 2012; Marjon et al., 2016). Tetraspanins may also be ubiquitinated at cytoplasmic sites, which contributes to their down-regulation (Lineberry et al., 2008; Wang Y. et al., 2012). An example structure of tetraspanin CD82 is depicted in Figure 2, with the post-translational modifications highlighted. How these tetraspanin post-translational modifications impact signal transduction will be addressed in more detail later in this review.

Through their function as molecular scaffolds, tetraspanins contribute to organismal development, reproduction, and immunity (Kaji et al., 2000, 2002; Le Naour et al., 2000; Miyado et al., 2000; García-Frigola et al., 2001; Levy and Shoham, 2005; Jarikji et al., 2009; van Spriel, 2011; Han et al., 2012). Consistent with their expression being primarily found in multicellular organisms, it is not surprising that many processes to which tetraspanins contribute center around cell-cell- interactions. Additionally, numerous tetraspanins are also associated with the development and progression of disease, in particular, with respect to cancer and cancer cell-niche interactions (Zoller, 2009; Hemler, 2013). Although tetraspanins do not have known adhesive ligands or catalytic activity, they contribute to cellular physiology by organizing molecules within the plasma membrane into microdomains.

The proposed function of tetraspanins is to organize the plasma membrane by facilitating the formation of what are

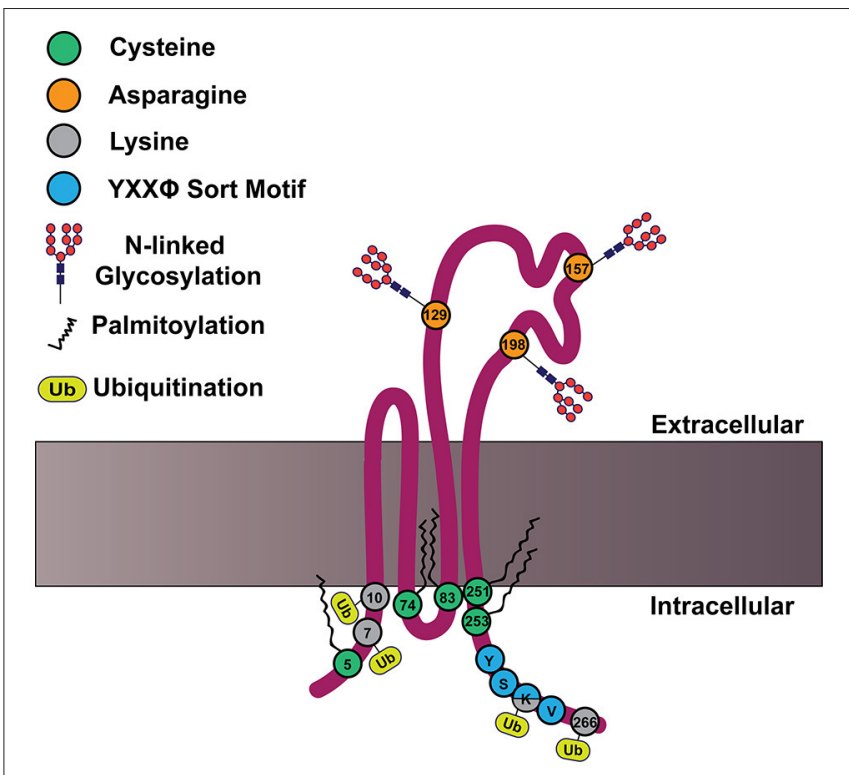

FIGURE 2 | CD82 structure and motifs. Cartoon depicting CD82 topology within the plasma membrane and important motifs. CD82 contains five membrane proximal cysteine residues (shown in green) at residues 5, 74, 83, 251 , and 253, which can be palmitoylated. There are three asparagine residues in EC2 (shown in orange) that are predicted to be $\mathrm{N}$-linked glycosylated at residues 129, 157, 198. There are four cytoplasmic lysine residues $7,10,263$, and 266 (shown in gray), which are predicted to be ubiquitinated. The C-terminal tyrosine based sort motif $(Y X X \varnothing)$ is depicted in blue at amino acids 261-264; for CD82 this motif is Tyr-Ser-Lys-Val.

termed tetraspanin enriched microdomains (TEMs). TEMs consist of homophilic and heterophilic interactions amongst tetraspanins, interactions between tetraspanins and other membrane proteins, as well as interactions between tetraspanins and proteins at the membrane/cytoplasm interface (Hemler, 2005; Charrin et al., 2009, 2014; Stipp, 2010). Moreover, these protein associations can occur through direct binding between tetraspanins and other proteins or through tetraspanin interactions with a common binding partner.

Interactions between tetraspanin and signaling molecules have been detected for various types of proteins, including adhesion and signaling receptors, and cytosolic signaling molecules, which are depicted in Figure 3. The downstream cellular consequences of these interactions vary, ranging from regulation of cellular adhesion, migration, contractility and morphology. As recent comprehensive reviews focused on tetraspanin regulation of immune signaling are available (Levy and Shoham, 2005; Halova and Draber, 2016), we will discuss other major classes of signaling molecules regulated by tetraspanins, as well as the cellular consequences of such regulations.

\section{TETRASPANINS AND ADHESION-MEDIATED SIGNALING}

One of the most prominent classes of adhesion receptors which tetraspanins are known to regulate is the integrin family of 


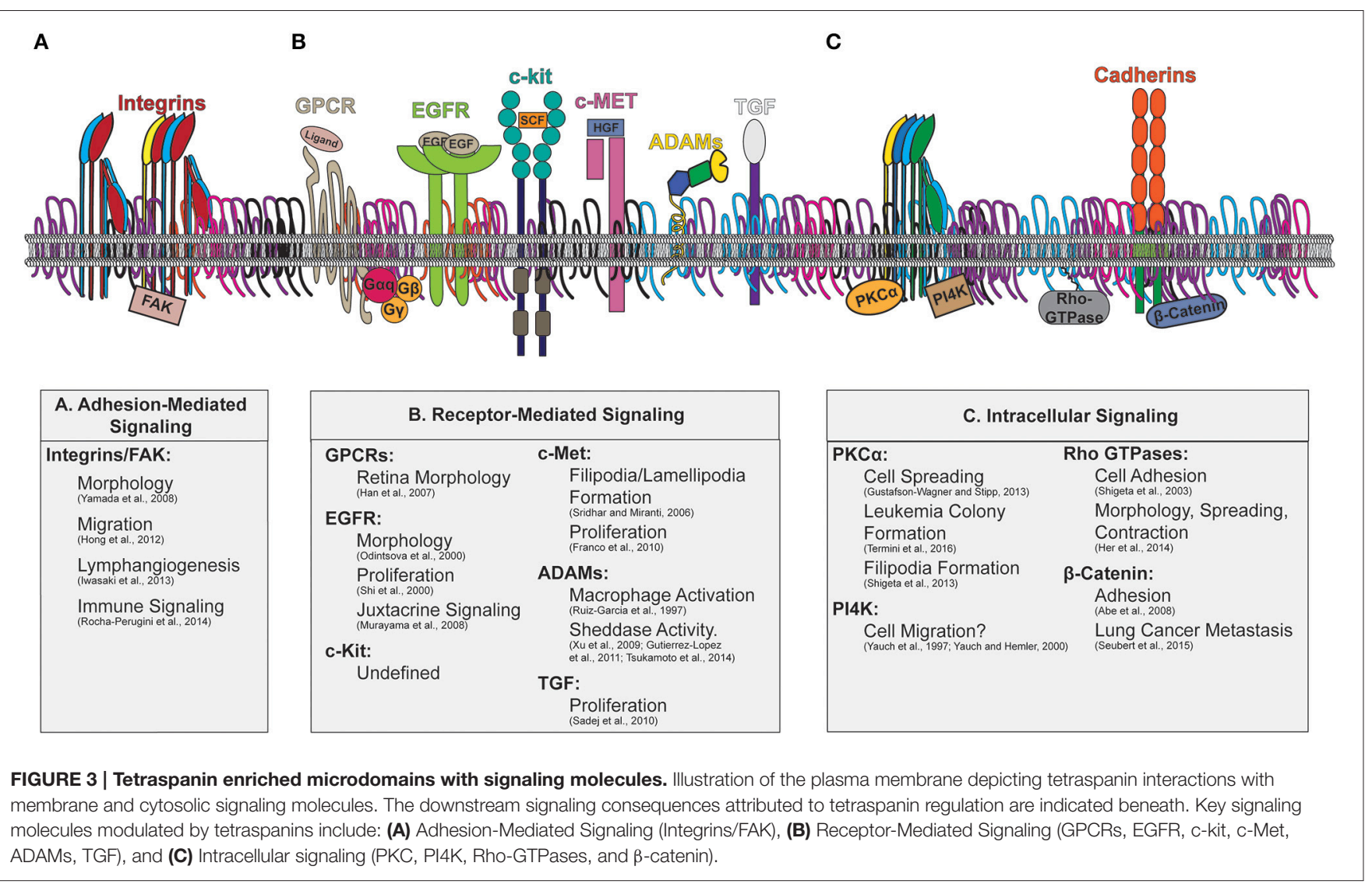

proteins. Integrins are heterodimeric proteins consisting of one $\alpha$ and one $\beta$ subunit, and this combination of subunits dictates their ligand specificity (Humphries et al., 2006). Numerous studies identified direct and indirect interactions between integrins and tetraspanins (Slupsky et al., 1989; Rubinstein et al., 1994; Berditchevski et al., 1996; Mannion et al., 1996; Yáñez-Mo et al., 2001, 1998; Stipp and Hemler, 2000; Berditchevski, 2001). Though integrins lack intrinsic catalytic activity, they propagate signals through a variety of cytoplasmic signaling molecules, many of which are components of focal adhesions (Schwartz, 2001). Through a combination of imaging and biochemical studies, researchers showed that tetraspanins colocalize with the focal adhesion proteins vinculin and talin as well as myrstoylated alanine-rich C-kinase substrate (MARCKS), which is involved in PKC-mediated signaling (Berditchevski and Odintsova, 1999). Moreover, signaling downstream of integrins is also mediated by the focal adhesion kinase, which is further regulated by tetraspanins as indicated below.

\section{Focal Adhesion Kinase}

Focal adhesion kinase (FAK) is a cytosolic protein which can interact directly with the integrin cytoplasmic tail, thereby allowing integrins to link to the actin cytoskeleton and promote downstream signaling (Schlaepfer et al., 1999). Immunoprecipitation studies demonstrated that tetraspanins CD9, CD63, CD81, CD82, and CD151 interact with the phosphorylated form of FAK (Berditchevski and Odintsova,
1999). Additionally, cells plated on anti-tetraspanin monoclonal antibodies demonstrated reduced FAK phosphorylation, further suggesting that tetraspanin scaffolding can contribute to FAK activation.

As suggested, a number of tetraspanins have been implicated in FAK regulation. It was shown that the siRNA knockdown of CD151 resulted in diminished phosphorylation of FAK, p130Cas, paxillin, and Src (Yamada et al., 2008). In fact, treatment with a CD151 monoclonal antibody, which reduced CD151 interactions with $\alpha 3 \beta 1$, also led to a reduction in FAK phosphorylation. In an attempt to rescue this phenotype, control or CD151 knockdown cells were treated with a $\beta 1$ integrin activating antibody and these data demonstrated that FAK phosphorylation could not be rescued under enforced integrin activation. As such, this study provides evidence that tetraspanins may regulate integrin-mediated signaling through a mechanism independent of initial integrin activation. The authors quantified FAK autophosphorylation (Tyr397), which is a FAK modification stimulated by integrin clustering (Schlaepfer et al., 1999). As tetraspanins have been previously demonstrated to regulate integrin clustering (van Spriel et al., 2012; Termini et al., 2014), perhaps the loss of CD151 diminishes integrin clustering, thereby reducing FAK phosphorylation. Additionally, the presence of CD151 increased FAK and Src phosphorylation in response to plating on extracellular matrix components, which modulated GTPase activation and downstream cell migration (Hong et al., 2012). The authors demonstrated that there is a greater increase 
in FAK and Src activation in response to plating on laminin than fibronectin, which is consistent with previous findings that CD151 is closely associated with laminin binding integrins (Berditchevski et al., 2002; Stipp, 2010).

Another tetraspanin identified to regulate FAK activity is CD9. In the case of lymphatic dermal endothelial cells, CD9 knockdown diminished FAK phosphorylation in response to VEGF-1 administration, demonstrating that tetraspanin regulation of FAK signaling can occur through multiple activating stimuli (Iwasaki et al., 2013). The authors further demonstrated that this CD9-mediated reduction in postadhesion signaling impaired lymphangiogenesis. Consistent with previous studies of CD151 (Yamada et al., 2008), RochaPerugini et al. demonstrated that silencing of CD151 or CD9 reduced the expression of phospho-FAK and phospho-ERK in response to T-cell engagement (Rocha-Perugini et al., 2014). A decrease in the accumulation of activated $\beta 1$ integrins and phospho-FAK was also detected at the immune synapse in CD9 and CD151 knockdown cells, suggesting that CD9 and CD151 promote the recruitment to and retention of integrins at the immune synapse, which results in diminished integrin downstream signaling. Therefore, the influence that tetraspanins have on integrin localization provides a critical means to regulate integrin-mediated signaling.

Though not technically considered a tetraspanin, the L6 tetraspan protein, TM4SF5, has sequence characteristics and structural properties similar to tetraspanins (Wright et al., 2000). It was shown that the intracellular loop of tetraspan TM4SF5 is critical for promoting an interaction between TM4SF5 and FAK (Jung et al., 2012). The authors performed in vitro pulldown assays using the $\mathrm{N}$ - or C-terminal cytoplasmic regions of TM4SF5 or the TM4SF5 intracellular loop to assess FAK binding. It was found that only the intracellular loop interacted with FAK, although the precise sites of association remain unknown. Future studies focused on identifying the particular amino acid residues within tetraspans that promote this association may offer potential targets to attenuate FAK signaling, which can be deregulated in numerous types of cancer (Sulzmaier et al., 2014).

\section{TETRASPANINS AND RECEPTOR-MEDIATED SIGNALING}

\section{G-Protein Coupled Receptors}

G-protein coupled receptors (GPCRs) are seven membranespanning proteins that transmit signals with the help of intracellular G proteins (Kobilka, 2007). Upon ligand binding, GPCRs can be coupled to $G \alpha, G \beta$, and $G \gamma$ subunits to activate numerous cellular responses including calcium and potassium channel regulation, as well as phospholipase C (PLC) and phosphoinositide 3-kinase (PI3K) signaling (Tuteja, 2009). With the use of model systems such as Drosophila, it was determined that tetraspanins can regulate GPCR-mediated signaling. For example, the Drosophila-specific tetraspanin, Sunglasses or Sun, is required for the light-induced down-regulation of rhodopsin, a light-sensitive GPCR (Xu et al., 2004). Interestingly, Sun was concentrated in the retina and removal of Sun resulted in retinal degeneration. Moreover, the authors determined that in flies with reduced Sun expression, extended exposure to light resulted in the diminished ability to down regulate rhodopsin. In line with these findings, Sun is most closely related to human tetraspanin, CD63, which is enriched within the lysosome (Metzelaar et al., 1991). Therefore, it is likely that Sun assists with GPCR signal attenuation by directing its endosomal trafficking in a similar manner to CD63. Additionally, an interaction between Sun and the Gq subunit of rhodopsin was identified, which was further proposed to help Sun promote the endocytosis of rhodopsin (Han et al., 2007).

The regulation of GPCRs by human tetraspanins has also been explored. It was shown that the GPCR, GPR56, associates with tetraspanins CD9 and CD81 (Little et al., 2004; Xu and Hynes, 2007), two tetraspanins which have also been demonstrated to interact with one another (Stipp et al., 2001). Through the use of mass spectrometry, it was also determined that the $G$ protein subunits, $\mathrm{G} \alpha_{11} \mathrm{G} \alpha_{\mathrm{q}}$ and $\mathrm{G} \beta$ associate with $\mathrm{CD} 81$ and further immunoprecipitation studies demonstrated that this association is not detected with tetraspanins CD63 or CD151 (Little et al., 2004). The authors postulate that perhaps the regulatory role of tetraspanins with respect to GPCRs may be to enhance ligand binding and downstream signaling, though this has yet to be directly tested. Important future studies will involve the analysis of downstream signaling through tetraspanin-mediated changes in GPCRs, including the potential regulation of GPCR-ligand affinity.

\section{Epidermal Growth Factor Receptor}

In addition to GPCRs (Metzelaar et al., 1991; Xu et al., 2004; Han et al., 2007) and integrins (He et al., 2005; Winterwood et al., 2006; Termini et al., 2014), tetraspanins have also been demonstrated to regulate the trafficking and signaling downstream of the epidermal growth factor receptor (EGFR). EGFR is a transmembrane receptor that can be activated by numerous ligands including epidermal growth factor (EGF) and transforming growth factor- $\alpha$ (TGF- $\alpha$ ). Ligand binding induces EGFR dimerization, which enhances EGFR catalytic activity (Jura et al., 2009; Valley et al., 2015). Moreover, EGFR endocytosis can serve as both a positive and negative regulatory signaling mechanism (Tomas et al., 2014). The contribution of tetraspanins in mediating EGFR trafficking has been extensively studied (Odintsova et al., 2000, 2003; Berditchevski and Odintsova, 2007).

Through a series of immunoprecipitation studies, it was shown that tetraspanin CD82 associates with EGFR and the overexpression of CD82 controls the phosphorylation kinetics of EGFR, Grb2, and Shc (Odintsova et al., 2000). It was determined that this regulation mediates the morphological response of HB2 cells to EGF stimulation. Interestingly, in cells expressing CD82, there was a more rapid down-regulation of EGFR upon EGF stimulation compared to cells that do not express CD82, indicating that CD82 contributes to EGFR down-regulation through modified internalization kinetics. This led the authors to suggest that the presence of CD82 modulates the signaling potency of the receptor even before it is activated. Furthermore, the authors speculate that the combination of reduced CD82 and 
increased EGFR expression may lead to uncontrolled signaling. Therefore, CD82, and likely other tetraspanins, may provide a means to attenuate signaling through modulations in EGFR trafficking. A follow-up study found that CD82 negatively regulates ligand-induced dimerization of EGFR, but does not affect the dimerization of ErbB2 or ErbB3 (Odintsova et al., 2003). Although the authors did not examine the downstream effects of altered dimerization, they suggest that the differential compartmentalization of EGFR by CD82 might alter cellular signaling.

Further studies examined the role of the vesicular associated membrane protein (VAMP), TI-VAMP, and CD82 in regulating the surface dynamics of EGFR. In this study, knockdown of CD82 led to increased EGFR endocytosis upon EGF stimulation through increased AP-2 recruitment (Danglot et al., 2010). Furthermore, CD82 knockdown also altered the EGFR diffusion patterns on the plasma membrane and reduced ERK phosphorylation upon EGF stimulation, providing evidence that tetraspanins can regulate the spatial dynamics of proteins for controlling downstream signaling. This report provides a unique mechanism by which CD82, through cooperation with TI-VAMP and AP-2, can regulate EGFR signaling and surface dynamics. Moreover, the authors propose that these regulatory mechanisms may be in part controlled by CD82-mediated alterations in actin dynamics or the membrane lipid composition.

EGFR regulation by CD82 was also shown to mediate ganglioside production. More specifically, the overexpression of CD82 in combination with inhibition of ganglioside production resulted in increased EGFR phosphorylation in response to EGF stimulation (Li Y. et al., 2013). The authors speculate that significant interplay occurs between glycosphingolipid enriched microdomains and TEMs, which cooperatively regulate cellular signaling. The overexpression of CD82 might promote EGFR clustering, which may stimulate dimerization and thereby enhance downstream EGFR signaling. Alternatively, the reduction in ganglioside production might improve EGFR phosphorylation by reorganizing the receptors into clusters within TEMs, since gangliosides have been demonstrated to contribute to TEM organization (Odintsova et al., 2006).

Beyond the prominent role of CD82 in regulating EGFR, additional studies also identified CD9 as a mediator of EGFR signaling. With the use of an autocrine system of MDCK cells coexpressing CD9 and TGF- $\alpha$, TGF- $\alpha$ stimulation promoted EGFR activation (Shi et al., 2000). The authors also utilized a paracrine system whereby CHO cells expressing TGF- $\alpha$ alone or TGF- $\alpha$ and CD9 together were plated with 32D cells expressing EGFR. This experiment demonstrated that co-expression of TGF- $\alpha$ and CD9 increases EGFR activation, although the precise mechanism by which CD9 modulates EGFR signaling remains unclear. Regardless, this study provides unique insight into how CD9 may regulate cellular signaling initiated through contact between adjacent cells. Interestingly, another report investigated the effect of CD9 expression on EGFR signaling, finding that increased expression of CD9 resulted in decreased phosphorylation of EGFR, Shc, and total Grb2 expression (Murayama et al., 2008). Though these studies demonstrate opposing effects of CD9 on EGFR, they also indicate that TNF- $\alpha$ plays a role in mediating EGFR activation through CD9. These studies open the possibility that other tetraspanins such as CD82 may also work in concert with TNF- $\alpha$, similar to CD9 and TNF- $\alpha$ in mediating EGFR activation. Therefore, future analyses would benefit from examining the interplay of TNF- $\alpha$ with other tetraspanins in regulating EGFR signaling.

\section{c-Kit}

The stem cell factor receptor or c-Kit (CD117) is a receptor tyrosine kinase that binds to its ligand, stem cell factor (SCF), which is also known as steel factor (SLF) or kit ligand (Lennartsson and Rönnstrand, 2012). c-Kit signaling can activate several signaling cascades, including PI3K, Src family kinases, and MAPK to name a few. Moreover, c-Kit mediated signaling can control numerous cellular processes including migration, survival and the differentiation of hematopoietic progenitor cells. With the use of immunoprecipitation studies, it was determined that c-Kit associates with tetraspanins $\mathrm{CD} 9, \mathrm{CD} 63$, and CD81 and this interaction was enhanced upon treatment with SCF (Anzai et al., 2002). Although the authors found increased phosphorylation of c-Kit within the immunoprecipitated fraction, they determined that this does not enhance kinase activity in response to SCF treatment. Rather, the kinetics of SCF binding to c-Kit were altered when c-Kit associated with $\mathrm{CD} 63$. The authors suggest that this might be because free c-Kit is internalized upon SCF binding, implying that perhaps the CD63/c-Kit complex is more stable on the cellular surface. While this study alludes to a role for tetraspanins in regulating c-Kit phosphorylation, further analysis is necessary to determine the downstream consequences of tetraspanin mediated c-Kit activation. Additionally, the possibility that tetraspanins, such as CD63, might stabilize c-Kit and modulate signaling through alterations in protein trafficking could have significant impact on specific leukemias where c-Kit expression and activation are known to be dysregulated (Ikeda et al., 1991; Goemans et al., 2005; Boissel et al., 2006; Corbacioglu et al., 2006; Paschka et al., 2006).

\section{c-Met}

c-Met is a receptor tyrosine kinase that can activate numerous pathways to promote cellular survival, motility, and proliferation (Birchmeier et al., 2003). Hepatocyte growth factor (HGF) binding to c-Met causes c-Met dimerization, which helps to initiate various cellular signaling cascades including AKT, ERK/MAPK, and JNK (Organ and Tsao, 2011). Furthermore, the overexpression of CD82 diminished the phosphorylation of c-Met in response to integrin ligand engagement, resulting in reduced Src phosphorylation (Sridhar and Miranti, 2006). In the case of invasive tumor situations, the authors' data suggest that the loss of CD82 leads to enhanced activation of c-Met through integrin activation. Although the regulatory mechanism remains unknown, this study provides a clear indication that tetraspanins can modulate c-Met mediated signaling downstream of integrin engagement.

It was also shown through immunoprecipitation studies that CD82 and c-Met interact (Takahashi et al., 2007). Moreover, the authors demonstrated that upon the ectopic expression of 
CD82, activation of c-Met with HGF led to increased formation of lamellipodia and filipodia through modulations in GTPase activities. Additionally, the ectopic expression of CD82 also prevented c-Met association with Grb2 and PI3K, implicating that CD82 has an inhibitory role with respect to these binding events. As such, perhaps the Grb2 and PI3K binding sites within c-Met become inaccessible in the presence of the c-Met/CD82 interaction.

The regulatory role of CD82 with respect to c-Met-mediated signaling has also been extended to controlling ERK1/2 and AKT signaling in hepatocellular carcinoma cells (Li Y. et al., 2013). An alternative report focused on CD151 with respect to Met signaling, showing that knockdown of CD151 led to diminished HGF-induced proliferation (Franco et al., 2010). The researchers determined that CD151 knockdown decreased tyrosine phosphorylation of the $\beta 4$ integrin subunit, which decreased MAPK signaling through ERK in response to HGF. Therefore, this study suggests that the c-Met-CD151- $\beta 4$ complex is critical for MAPK signaling. While the molecular link between tetraspanins and ERK or AKT downstream of c-Met remains an open question, this work implicates integrins as a possible connection.

\section{Transforming Growth Factor Signaling}

Transforming growth factor $\alpha$ (TGF- $\alpha$ ) is synthesized as a transmembrane protein, which can become cleaved by metalloproteinases to release soluble TGF- $\alpha$ (Pandiella and Massagué, 1991). This cleavage is stimulated by endotoxins (Breshears et al., 2012; Liu Z. et al., 2013) and ROS (Boots et al., 2009) and is mediated primarily by ADAM17 (Peschon et al., 1998), but also by ADAM10 (Hinkle et al., 2003) and MeprinA (Bergin et al., 2008; Minder et al., 2012; Singh and Coffey, 2014). Moreover, TGF- $\alpha$ can interact with and activate EGFR on neighboring cells (Schlessinger and Ullrich, 1992; Thorne and Plowman, 1994; Moral et al., 2001). An association between CD9 and transmembrane TGF- $\alpha$ was identified and found to be dependent on the TGF- $\alpha$ ectodomain (Shi et al., 2000). The experimenters illustrated that the cleavage of TGF$\alpha$ was inhibited by CD9, implicating a role for the association between CD9 and TGF- $\alpha$ as a means of protecting TGF- $\alpha$ from proteolytic cleavage. The authors suggested that the inhibition of TGF- $\alpha$ cleavage feeds into enhanced TGF- $\alpha$ induced EGFR activation, which can increase cellular proliferation. This study provides evidence that tetraspanins, such as CD9, can promote cellular signaling by stabilizing transmembrane proteins, thereby providing a potent activation stimulus to mediate juxtacrine signaling. Protein kinase $\mathrm{C}$ (PKC) and MAPK signaling can also regulate TGF- $\alpha$ cleavage (Baselga et al., 1996; Fan and Derynck, 1999). As tetraspanins can regulate PKC and MAPK signaling (Zhang et al., 2001; Termini et al., 2016), a closer examination into the interplay between these molecules in mediating TGF$\alpha$ signaling may provide a more comprehensive view of the complex regulatory networks at play within TEMs.

A follow up study demonstrated that CD9 expression enhances TGF- $\alpha$ expression at the cell surface using MDCK cells (Imhof et al., 2008). Here, CD9 was shown to promote the trafficking of TGF- $\alpha$ from the Golgi to the cell surface by stabilizing the glycosylated and prodomain-removed forms of TGF- $\alpha$. Furthermore, the authors demonstrated that the expression of TGF- $\alpha$ and CD9 alters actin organization and focal adhesion formation, supporting the notion that the combination of CD9 and TGF- $\alpha$ expression produces dramatically different signaling responses than the expression of TGF- $\alpha$ alone. Therefore, the tetraspanin expression profile should be considered when characterizing TGF- $\alpha$ signaling, particularly in many cancers where TGF- $\alpha$ expression is thought to support cancer progression (Kenny and Bissell, 2007).

Additionally, the contribution of tetraspanins to the regulation of the TGF isoform TGF- $\beta 1$ has been assessed. Researchers used CD151 knockdown MDA-MB-231 cells and determined that in the presence of TGF- $\beta 1$, CD151 knockdown cells had a significantly decreased proliferative rate compared to control cells (Sadej et al., 2010). More specifically, in the CD151 knockdown cells, TGF- $\beta 1$ stimulation led to reduced p38 phosphorylation, resulting in decreased metastasis. Mechanistically, the authors propose that CD151 modulations of the plasma membrane may alter the distribution of TGF- $\beta 1$ receptors and downstream signaling. Future studies may focus on determining how CD151 modulates the molecular organization of the TGF receptor, as this may provide a mechanism to regulate downstream signaling.

\section{A Disintegrin and Metalloproteases}

The A Disintegrin and Metalloprotease (ADAM) family of transmembrane and secreted proteins contribute to the regulation of cellular adhesion, migration, proliferation, and signaling (Seals and Courtneidge, 2003). As the name states, ADAMs contain a disintegrin and a metalloprotease domain. While the metalloprotease domain can cleave extracellular matrix (ECM) components and mediate ectodomain shedding of cytokines, growth factors, the disintegrin domain can interact with integrins. Recent comprehensive reviews provide insight on the role that tetraspanins play in regulating membrane proteases, with a particular emphasis on their role in regulating ADAM10 and ADAM17 (Yáñez-Mo et al., 2011; Matthews et al., 2016). Initial reports demonstrated that ADAM10 is associated with CD9, CD81, and CD82, indicating that ADAM10 likely exists within TEMs. Interestingly, treatment with antitetraspanin antibodies stimulated the release of TNF- $\alpha$ and EGF in an ADAM10-mediated manner. Furthermore, through mass spectrometry studies and extensive immunoprecipitation studies, Tspan12 was found to associate with ADAM10, which contributed to the ability of ADAM10 to process amyloid precursor protein for shedding (Xu et al., 2009). Using several mutated TSPAN12 constructs, this association was determined to be regulated by EC1, the C-terminal tail and TSPAN12 palmitoylation. More recent co-immunoprecipitation studies revealed that the subgroup of TspanC8 tetraspanins (Tspan5, $10,14,15,17$, and 33) interact with ADAM10 (Dornier et al., 2012). Additionally, ADAM17 was also found to associate with tetraspanin CD9 in leukocytes and endothelial cells, which diminishes ADAM17-mediated TNF- $\alpha$ and ICAM-1 shedding. Interestingly, CD9 can regulate the catalytic activity of ADAM17 with regards to shedding of LR11 in monocytes, promonocytes 
and B-lymphoblastoid cell lines (Tsukamoto et al., 2014). As ADAMs are implicated in regulating various cancer cell types (Mochizuki and Okada, 2007), the role of tetraspanins in regulating ADAMs in malignant cells will provide significant insight and perhaps a means to attenuate aberrant ADAM activity.

ADAMs are produced as immature, inactive, preforms in the endoplasmic reticulum. During trafficking from the ER to the plasma membrane, the enzyme's prodomain is removed and ADAMs are then rendered catalytically active (Seals and Courtneidge, 2003). Interestingly, it was determined that TspanC8 contributes to ADAM10 maturation and ultimately the stabilization of ADAM10 at the cell surface (Prox et al., 2012). Furthermore, Tspan33 knockdown in erythrocytes resulted in diminished ADAM10 surface expression. Meanwhile, ADAM10 surface expression remained unchanged in platelets, demonstrating that tetraspanin regulation of ADAM10 is likely cell-type specific (Haining et al., 2012). Additionally, the role of Tspan33 in regulating ADAM10 for the control of macrophage activation was recently explored (Ruiz-García et al., 2016). Researchers utilized Tspan33 overexpressing Raw 264.7 cells and demonstrated that increased Tspan33 expression results in increased ADAM10 processing, consistent with the earlier aforementioned studies.

\section{TETRASPANINS AND INTRACELLULAR SIGNALING}

Although tetraspanins are known to primarily affect the properties of other membrane proteins, they have also been shown to regulate cytoplasmic signaling molecules. Signaling proteins are often recruited to the cytoplasmic interface of the plasma membrane where they initiate signaling and TEMs can serve as a potential membrane recruitment site. Therefore, in the following section, we will review how tetraspanins control the localization, kinetics, and signaling properties of cytosolic proteins.

\section{Protein Kinase C}

The protein kinase $\mathrm{C}$ (PKC) family of intracellular signaling proteins consists of isoforms, which are further classified into conventional, novel or atypical isoforms (Newton, 1995). PKCs can phosphorylate several targets, including the myosin light chain II (Liu X. et al., 2013), PKD2 (Waldron et al., 2001; Navarro and Cantrell, 2014), Ras GEFs (Jun et al., 2013), and the $\beta 1$ integrin tail (Stawowy et al., 2005), which collectively contribute to the regulation of cell proliferation, apoptosis, and adhesion amongst other cellular behaviors (Kang, 2014). The interaction between tetraspanins and PKC was originally demonstrated in K562 cells using an elaborate series of immunoprecipitation experiments (Zhang et al., 2001). The experimenters used phorbol 12-myristate 13-acetate (PMA), which mimics diacylglycerol (DAG) to activate PKC (Castagna et al., 1982). Under PMA stimulated conditions tetraspanins $\mathrm{CD} 9, \mathrm{CD} 53$, CD81, and CD82 individually interact with $\mathrm{PKC} \alpha$ and not with PI3K. Additionally, they determined that CD81 and CD151 associate with PKC $\beta$ II. Moreover, in a PKC $\alpha$ pulldown, $\beta 1, \alpha 3$, and $\alpha 6$ integrins were detected in complex with PKC. Therefore, it was suggested that tetraspanins serve to link PKC to integrins. In order to assess the tetraspanin domains that control PKC associations, chimeric mapping was performed by replacing portions of $\mathrm{CD} 9$ with portions of the non-PKC associating tetraspanin, A15/Talla1. These findings demonstrated that PKC association with tetraspanins occurs outside of the short inner loop, the large outer loop, and transmembrane 3 or 4 .

A recent report also demonstrated that tetraspanin CD151 regulates skin squamous cell carcinoma through STAT3 and PKC $\alpha$ signaling (Li Q. et al., 2013). Utilizing wild type or CD151 ablated A431 epidermoid carcinoma cells, it was shown that the loss of CD151 reduces STAT3 activation in response to 12 O-Tetradecanoylphorbol-13-acetate (TPA) stimulation, which is another known activator of PKC $\alpha$. The authors found that PKC $\alpha$ only associates with $\alpha 6 \beta 4$ upon TPA stimulation when CD151 is present. Together, these data suggest that perhaps the role for CD151 is to recruit PKC $\alpha$ into close proximity with the $\alpha 6 \beta 4$ integrin, which ultimately aids in the phosphorylation of $\alpha 6 \beta 4$. As such, these data build upon previous implications that tetraspanins link PKC to integrins (Zhang et al., 2001), but also provide evidence that this scaffolding is important for epidermal proliferation and STAT3 activation.

Another interesting report investigated how CD9, CD81, and CD151 expression affects PKC $\alpha$ association with TEMs (Gustafson-Wagner and Stipp, 2013). It was demonstrated that $\mathrm{CD} 9 / \mathrm{CD} 81$ knockdown diminishes the ability for the $\alpha 3$ integrin to associate with $\mathrm{PKC} \alpha$, which delays cell spreading on laminin and directed migration. In contrast, CD151 knockdown enhanced the association of PKC $\alpha$ with the $\alpha 3$ integrin, while promoting cell migration on collagen-I. The authors propose that CD9/81 may serve as linkers of PKC to the $\alpha 3$ integrin subunit, or there might be an indirectly associating molecule at play. Furthermore, the authors propose that perhaps upon CD151 depletion, there is increased association between PKC and $\alpha 3$ due to the loss of CD151, which makes CD9/81 available to fully associate with $\alpha 3$, thereby promoting PKC-integrin association. This study provides substantial evidence that the roles of tetraspanins $\mathrm{CD} 9, \mathrm{CD} 81$, and $\mathrm{CD} 151$ are unique in their regulation of $\mathrm{PKC} \alpha$-integrin interactions.

Further examination into the regulatory role of tetraspanins with respect to PKC-mediated signaling has uncovered many unique cellular responses. For example, treatment of A431 cells with Calphostin C to inhibit PKC $\alpha$ reduced filipodia extensions as well as E-cadherin puncta formation, demonstrating the involvement of actin in tetraspanin-regulated PKC signaling (Shigeta et al., 2003). The authors suggest that CD151 directly or indirectly associates with $\mathrm{PKC} \alpha$, which they propose may activate Cdc42 to promote filipodia formation.

A more recent report from our laboratory demonstrated that $\mathrm{CD} 82$ regulates $\mathrm{PKC} \alpha$ signaling in acute myeloid leukemia (AML) (Termini et al., 2016). Using quantitative FRET imaging and KG1a AML cell lines that overexpress wild type CD82 or a palmitoylation deficient form of CD82 (Delandre et al., 2009), we found that upon PMA stimulation, PKC $\alpha$ was recruited to the plasma membrane where it associates with CD82. However, 
upon extended PMA stimulation, this PKC $\alpha / C D 82$ association is reduced in cells overexpressing the palmitoylation deficient form of CD82, demonstrating that the palmitoylation of CD82 regulates the stability of the PKC $\alpha$ interaction. We went on to use super-resolution imaging to examine how the scaffolding properties of CD82 regulate the macromolecular clustering of PKC $\alpha$ and found that upon disruption of the CD82 scaffold, there is a significant reduction in the size of $\mathrm{PKC} \alpha$ clusters. Moreover, using CD82 knock-down cells, we found that while $\mathrm{PKC} \alpha$ is still recruited to the membrane upon PMA stimulation, large-scale PKC $\alpha$ clusters are not detected. This change in $\mathrm{PKC} \alpha$ clustering was then linked to alterations in downstream ERK1/2 signaling that influenced the aggressive phenotype of AML (Termini et al., 2016). Interestingly, the kinetics of PKC $\alpha$ oligomerization were recently quantified and modeled using HEK cells where they found that the intramolecular clustering of $\mathrm{PKC} \alpha$ contributes to downstream phosphorylation (Bonny et al., 2016). Collectively, these studies illustrate that the modulation of signaling molecule clusters may serve as an important regulatory mechanism for stabilizing and/or attenuating signal transduction pathways. Moreover, our work implicates tetraspanins as critical mediators of cluster size and stability. Future super resolution imaging studies focused on identifying how the clustering of tetraspanins can modulate downstream signaling through PKC and other molecules such as Rac or Cdc42 would be valuable to help clarify how tetraspanins and $\mathrm{PKC} \alpha$ mediate cytoskeletondependent cellular responses such as adhesion and migration.

An interesting link was also discovered between PKC and EGFR-mediated signaling that is enhanced by CD82. c-Cbl is an ubiquitin ligase recruited to EGFR where it assists with receptor down-regulation (Joazeiro et al., 1999). The authors found that PKC mediates c-Cbl phosphorylation upon EGF stimulation in CD82 expressing H2B cells (Odintsova et al., 2013). The phosphorylation of $\mathrm{c}-\mathrm{Cbl}$ serves as a negative regulator of enzyme function (Ryan et al., 2006), which may be responsible for inhibiting EGFR downregulation. Therefore, without CD82 present, EGFR can be quickly downregulated as PKC is not present to regulate c-Cbl. Collectively, these studies provide substantial evidence that implicates tetraspanins as signaling scaffolds that promote the close proximity of PKC with integrins, EGFR and cytoplasmic proteins like c-Cbl.

\section{Phosphatidylinositol 4-Kinase}

Phosphatidylinositol 4-kinase (PI4K) catalyzes the conversion of phosphatidylinositol (PI) to phosphatidylinositol 4-phosphate (PI4P), which is an important intermediate for lipid-mediated signaling (Clayton et al., 2013). A series of biochemical experiments demonstrated that PI4K exists within $\alpha 3$ integrin and CD63 containing TEMs (Berditchevski et al., 1997). The authors suggest that perhaps TEMs are responsible for linking the $\alpha 3 \beta 1$ integrin to PI4K. A follow up study from the same group explored this further, demonstrating that immunoprecipitation of $\alpha 3$ or CD151 yields similar levels of PI4K activity based upon PI4P production (Yauch et al., 1997). Additionally, using cells with diminished $\alpha 3$ expression, CD151 was pulled down, demonstrating that there is still PI4K associated with the complex. Conversely, immunodepletion of CD151 resulted in significantly diminished lipid kinase activity associated with $\alpha 3$, while CD63 and/or CD81 deletion did not have as significant of an effect. Collectively, these data implicate CD151 as a critical linker between PI4K and $\alpha 3 \beta 1$, which the authors suggest may support cell migration.

A subsequent follow up study demonstrated that PI4K associates with tetraspanins A15/TALLA1, CD63, CD151, CD9, and CD81, however it does not appear to associate with NAG-2, CD53, CD37, or CD82 (Yauch and Hemler, 2000). Moreover, PI3K and PI4P5K activity were not detected in CD63, CD81, and CD151 complexes, indicating that perhaps the association is specific to PI4K. Studies with CD9/CD82 chimeras were unsuccessful at determining the site of association with PI4K. Therefore, a closer examination into the structural domains within tetraspanins that contribute to their association with PI4K could provide insight into the mechanism by which tetraspanins may regulate the catalytic activity of PI4K and downstream responses.

\section{GTPases}

Rho GTPases mediate signal transduction by switching between a GTP-bound (active) and GDP-bound (inactive) state (Bishop and Hall, 2000). There are numerous effector proteins downstream of GTPases including PI3K, PI-4-P5K, MEKK1, and DAG kinase. The Rho family GTPases Rac1, RhoA, and Cdc42 as well as the Ras family of GTPases translocate to the plasma membrane upon activation (Collins, 2003), where their regulation by tetraspanins continues to be defined.

For example, CD151 was demonstrated to regulate Cdc42 for the control of cellular adhesion. Using A431 cells, CD151 antibody treatment or CD151 overexpression was found to increase Cdc42 activation, which the authors suggest controls actin reorganization, promoting filopodia-based adhesions (Shigeta et al., 2003). Another study assessed how the coexpression of CD9 and TGF- $\alpha$ regulates GTPase signaling, finding increased and decreased levels of activated Racl and RhoA respectively, with $\mathrm{Cdc} 42$ levels remaining unchanged upon coexpression of CD9 and TGF- $\alpha$ (Imhof et al., 2008). This shift in signaling was determined to be due to enhanced EGFR signaling, which ultimately contributed to enhanced stress fiber formation. Additionally, the overexpression of CD82 was shown to decrease the proportion of GTP-bound Rac1, while RhoA and Cdc42 levels remained unchanged (Liu et al., 2012).

Previous work also demonstrated that CD151 promotes the association between CD151- $\beta 1$ complexes and Ras, Rac1 or Cdc42. Immunofluorescence imaging showed that CD151 regulates the translocation of Racl and Ras to the membrane and promoted colocalization with $\beta 1$ integrins (Hong et al., 2012). Interestingly, through the use of a CD151 chimera with disrupted $\alpha 3 \beta 1$ integrin association, the authors showed that this mutant is unable to recruit Rac1 to the membrane. Therefore, integrins also have the capacity to link GTPases to tetraspanins in a manner similar to what was previously proposed for PKC and tetraspanins (Zhang et al., 2001; Li Q. et al., 2013). An 
association between Rac1 and the C-terminal, cytoplasmic region of CD81 has also been suggested based on the use of an eight amino acid C-terminal tail peptide (Tejera et al., 2013). Future experiments that mutate or delete the CD81 C-terminal tail will be important to demonstrate that such a mutation eliminates $\mathrm{Racl}$ association, further validating the interaction. Furthermore, upon EGF stimulation, it was shown that knockdown of CD81 increases Rac activation. A more recent study identified a correlation between CD9 expression and GTP bound Rac1 expression in acute lymphoblastic leukemia patient samples (Arnaud et al., 2015). Moreover, this group also determined that the C-terminal tail of CD9 is important for regulating Rac1 activation. Interestingly, the C-terminal region of CD9 has two known palmitoylation sites (Charrin et al., 2002), and Rac can also be palmitoylated (Tsai and Philips, 2012). Therefore, it is possible that these post-translational modifications may help to anchor tetraspanins and GTPases into similar membrane compartments.

Tetraspanin regulation of RhoA signaling, which can promote changes in cytoskeletal organization, has also been characterized (Sit and Manser, 2011). Using human aortic smooth muscle cells, CD9 knockdown decreased the expression of GTP-bound RhoA, leading to defects in cellular morphology, spreading and contraction (Herr et al., 2014). The authors suggest that integrins are involved in CD9-mediated alterations in RhoA activation by possibly stabilizing integrin-ECM interactions, augmenting RhoA activation. Interestingly, a recent report demonstrates that the loss of CD151 in breast cancer cells resulted in increased RhoA activation as quantified using FRET biosensors (Novitskaya et al., 2014). These data are contrary to Hong et al. (2012), who showed no change in Rho activation upon CD151 depletion. However, the change in FRET efficiency detected was $<5 \%$, which would likely be below the detection of the small GTPase protein pull-down assays used by Hong et al. Moreover, a separate report demonstrated that the knockdown of CD151 in human dermal microvascular endothelial cells resulted in an increase in RhoA-GTP and decreased Rac1-GTP (Zhang et al., 2011). Future studies focused on the mechanism by which tetraspanins can modulate GTPase activation will be important for determining how certain tetraspanins may be targeted to control specific GTPase activities in specialized cell types.

\section{$\beta$-Catenin}

$\beta$-catenin is a component of the Wnt signaling pathway that binds to the cytosolic portion of cadherins to initiate cellular signaling (Valenta et al., 2012). Through this complex formation, $\beta$-catenin promotes the internalization and recycling of $\mathrm{E}$ cadherin, thereby destabilizing the complex and ultimately reducing cell-cell adhesion. Researchers determined that ectopic CD82 expression in h1299 cells relocalizes $\beta$-catenin to E-cadherin at the cell membrane, which stabilizes complex formation (Abe et al., 2008). Furthermore, they showed that ectopic CD82 expression increased cancer cell aggregation. To assess the downstream consequences of altered $\beta$-catenin localization, the authors stimulated cells with EGF or hepatocyte growth factor (HGF), demonstrating that ectopic expression of CD82 diminished $\beta$-catenin phosphorylation. While $\beta$ catenin phosphorylation is known to destabilize the E-cadherin complex, the mechanism for tetraspanin involvement remains to be clearly defined. Based on our previous work with N-cadherin (Marjon et al., 2016), we speculate that the CD82 scaffold might contribute to cadherin clustering, which may stabilize $\beta$-catenin membrane interactions, thereby protecting $\beta$-catenin from phosphorylation and down-regulation.

More recently, CD63 was shown to stabilize $\beta$-catenin signaling. In this study, shRNA knockdown of CD63 decreased $\beta$-catenin protein expression levels, which was suggested to occur through diminished levels of inactive GSK3 $\beta$, leading to increased levels of phosphorylated $\beta$-catenin (Seubert et al., 2015). Furthermore, decreased levels of the $\beta$-catenin targets, MMP-2 and PAI-1, were detected, demonstrating CD63mediated changes in downstream $\beta$-catenin signaling. The authors went on to find that the reduced expression of CD63 diminishes the metastatic potential of lung cancer cells, while the overexpression promoted tumor aggressiveness. However, modulations in signaling induced by CD63 overexpression were not explored. A previous study provided evidence that disrupting the interaction between the $\alpha 3 \beta 1$ integrin and CD151 enhanced $\beta$-catenin phosphorylation (Chattopadhyay et al., 2003). Therefore, it is plausible that the combination of integrins and tetraspanins serves to stabilize $\beta$-catenin within TEMs.

\section{TETRASPANIN POST-TRANSLATIONAL MODIFICATIONS AND SIGNALING}

\section{Palmitoylation}

S-palmitoylation is the addition of a 16-carbon fatty acid chain, palmitate, to cysteine residues of either cytoplasmic or membrane proteins (Blaskovic et al., 2013). Palmitoylation of cytoplasmic proteins promotes membrane anchoring, while palmitoylation of membrane proteins facilitates trafficking and membrane organization. Palmitoylation has been confirmed for tetraspanins CD9, CD151 (Yang et al., 2002), CD81 (Delandre et al., 2009), and CD82 (Mazurov et al., 2007), however other tetraspanins also contain conserved cysteine residues that are predicted to be palmitoylated. The defined role for palmitoylation is to modulate TEM formation (Yang et al., 2004). Therefore, we took a closer examination of how tetraspanin palmitoylation contributes to the signaling that occurs downstream of TEM associated proteins.

For example, the expression of the palmitoylation deficient form of CD151 weakened its association with integrins (Berditchevski et al., 2002), resulting in diminished phosphorylation of AKT in response laminin-5 engagement. These data indicate that palmitoylation-mediated disruption of TEMs can reduce downstream signaling responses. Additionally, a palmitoylation deficient form of Tetraspanin 12 was shown to have diminished association with ADAM10, resulting in decreased ADAM10 activity as assessed by APP shedding (Xu et al., 2009). Recent work from our lab has shown 
that overexpression of a palmitoylation-deficient form of CD82 diminishes PKC membrane stabilization, reducing ERK1/2 activation, and downstream leukemia colony formation (Termini et al., 2016). Collectively, these studies demonstrate that tetraspanin palmitoylation contributes significantly to the regulation of downstream cellular signaling. Intracellular signaling molecules such as Ras (Eisenberg et al., 2013), Rac (Tsai and Philips, 2012), and PKC (Ford et al., 1998) can themselves be palmitoylated to assist with their membrane anchorage. As tetraspanin palmitoylation is thought to regulate lateral protein associations within TEMs, perhaps tetraspanin palmitoylation functions in concert with the palmitoylation of cytoplasmic proteins to produce stable membrane interactions critical for sustained signaling.

\section{Glycosylation}

Although the large extracellular loop of many tetraspanins has been demonstrated to have one or more potential $\mathrm{N}$ linked glycosylation sites, little is known about the functional consequences of this post-translational modification. The $\mathrm{N}$ glycosylation pattern of CD82 was recently identified using proteomics and glycomics, determining that there are three putative N-glycosylation sites (Wang H. et al., 2012). Previously, these sites were suggested to regulate apoptosis, however the researchers did not examine the signaling that led to these apoptotic changes (Ono et al., 1999). Interestingly, the photoreceptor-specific tetraspanin retinal degeneration slow (RDS) can also be glycosylated (Kedzierski et al., 1999; Conley et al., 2012). More recently, the function of RDS glycosylation was re-examined by expressing a glycosylation deficient version of RDS in mice, which identified differential functional outcomes in cones vs. rod photoreceptor cells (Stuck et al., 2015). Moreover, the authors determined that glycosylation regulates the formation of RDS complexes with another tetraspanin ROM1, demonstrating that glycosylation can modulate tetraspanin complex formation. A recent report from our laboratory examined the role of CD82 glycosylation with respect to acute myeloid leukemia homing (Marjon et al., 2016). In this study, we demonstrated that mutation of the three glycosylation sites within CD82 to inhibit glycosylation resulted in increased AML cell homing to the bone marrow, which we linked to increased molecular packing of $\mathrm{N}$-cadherin via super resolution imaging. Although we have yet to examine signaling deficits in cells with disrupted CD82 glycoslation, it is possible that these changes in the molecular organization of $\mathrm{N}$-cadherin may modulate the activation or stability of p120 catenin or $\beta$-catenin signaling downstream of $\mathrm{N}$-cadherin.

\section{Ubiquitination}

Protein ubiquitination is important for regulating cellular signaling by selectively targeting proteins for degradation. Both CD81 and CD151 were shown to interact with gene related to anergy in lymphocytes (GRAIL), which promotes tetraspanin ubiquitination, ultimately downregulating surface tetraspanin expression (Lineberry et al., 2008). Interestingly, it was determined that these tetraspanins can only be ubiquitinated at their $\mathrm{N}$-terminus. Through mutational studies, it was shown that mutation of $\mathrm{K} 8$ and $\mathrm{K} 11$ diminished the ubiquitination of CD81, while mutation of $\mathrm{K} 8, \mathrm{~K} 11$, and $\mathrm{K} 17$ ablated the ubiquitination of CD151. More recently it was demonstrated that TSPAN6 interacts with the adaptor mitochondrial antiviral signaling (MAVs) in $293 \mathrm{~T}$ cells to inhibit RIG-I-like receptor (RLR) mediated signaling (Wang Y. et al., 2012). The authors went on to show that induction of RLR signaling promoted the ubiquitination of TSPAN6 at K11, K16, and K43, which are sites found within the TM1 of TSPAN6. Additionally, the authors determined that TSPAN6 ubiquitination serves to inhibit the formation of the signalosome, effectively down-regulating RLR signaling. As ubiquitination can target proteins for degradation, we suspect that tetraspanin ubiquitination will be a regulatory mechanism to allow for specific and efficient attenuation of tetraspanin-mediated signaling.

\section{CONCLUDING REMARKS}

Tetraspanins and their formation into TEMs enable the compartmentalization of membrane receptors within the plasma membrane. In this review, we focus on how tetraspanins also serve to connect these membrane-associated molecules with intracellular signaling complexes. It is now clear that tetraspanins regulate diverse cell signaling pathways that impact a breadth of biological processes. However, though numerous signaling molecules have been demonstrated to associate with tetraspanins, the mechanisms by which tetraspanins precisely modulate signal transduction remains relatively undefined. Future studies focused on how domains and motifs within tetraspanins promote or perhaps attenuate cellular signaling will help us understand the specific mechanisms used by this family of proteins to control signaling. Many laboratories are now using sophisticated imaging techniques to provide novel insight into the spatiotemporal interactions mediated by tetraspanins and TEMs. These studies will help to define how the scaffolding properties of tetraspanins contribute to the formation, stabilization and dynamics of signal transduction complexes at the plasma membrane. Moreover, these studies may provide the needed insight to establish tetraspanins and TEMs as potential therapeutic targets for the modulation of aberrant signal transduction that mediates processes such as inflammation, wound healing, and various types of cancer.

\section{AUTHOR CONTRIBUTIONS}

CT and JG wrote and edited the manuscript. CT created the figures. All authors reviewed the manuscript.

\section{FUNDING}

This work was supported by an F31 Fellowship from the National Heart, Lung, and Blood Institute (F31HL124977 to CT), an American Heart Association Scientist Development Grant (13SDG14630080 to JG), and an NIH investigator grant (RO1HL122483-01 to JG). Support was also provided from NIH P50 GM085273 (B. Wilson). 


\section{REFERENCES}

Abe, M., Sugiura, T., Takahashi, M., Ishii, K., Shimoda, M., and Shirasuna, K. (2008). A novel function of CD82/KAI-1 on E-cadherin-mediated homophilic cellular adhesion of cancer cells. Cancer Lett. 266, 163-170. doi: 10.1016/j.canlet.2008.02.058

Albers, T., Maniak, M., Beitz, E., and von Bülow, J. (2016). The C isoform of dictyostelium tetraspanins localizes to the contractile vacuole and contributes to resistance against osmotic stress. PLoS ONE 11:e0162065. doi: 10.1371/journal.pone. 0162065

Anzai, N., Lee, Y., Youn, B. S., Fukuda, S., Kim, Y. J., Mantel, C., et al. (2002). $\mathrm{C}$-kit associated with the transmembrane 4 superfamily proteins constitutes a functionally distinct subunit in human hematopoietic progenitors. Blood 99, 4413-4421. doi: 10.1182/blood.V99.12.4413

Arnaud, M. P., Vallée, A., Robert, G., Bonneau, J., Leroy, C., Varin-Blank, N., et al. (2015). CD9, a key actor in the dissemination of lymphoblastic leukemia, modulating CXCR4-mediated migration via RAC1 signaling. Blood 126, 1802-1812. doi: 10.1182/blood-2015-02-628560

Baselga, J., Mendelsohn, J., Kim, Y. M., and Pandiella, A. (1996). Autocrine regulation of membrane transforming growth factor-alpha cleavage. J. Biol. Chem. 271, 3279-3284. doi: 10.1074/jbc.271.6.3279

Berditchevski, F. (2001). Complexes of tetraspanins with integrins: more than meets the eye. J. Cell Sci. 114, 4143-4151.

Berditchevski, F., and Odintsova, E. (1999). Characterization of integrintetraspanin adhesion complexes: role of tetraspanins in integrin signaling. J. Cell Biol. 146, 477-492. doi: 10.1083/jcb.146.2.477

Berditchevski, F., and Odintsova, E. (2007). Tetraspanins as regulators of protein trafficking. Traffic 8, 89-96. doi: 10.1111/j.1600-0854.2006.00515.x

Berditchevski, F., Odintsova, E., Sawada, S., and Gilbert, E. (2002). Expression of the palmitoylation-deficient $\mathrm{CD} 151$ weakens the association of alpha 3 beta 1 integrin with the tetraspanin-enriched microdomains and affects integrin-dependent signaling. J. Biol. Chem. 277, 36991-37000. doi: 10.1074/jbc.M205265200

Berditchevski, F., Tolias, K. F., Wong, K., Carpenter, C. L., and Hemler, M. E. (1997). A novel link between integrins, transmembrane-4 superfamily proteins (CD63 and CD81), and phosphatidylinositol 4-kinase. J. Biol. Chem. 272, 2595-2598. doi: 10.1074/jbc.272.5.2595

Berditchevski, F., Zutter, M. M., and Hemler, M. E. (1996). Characterization of novel complexes on the cell surface between integrins and proteins with 4 transmembrane domains (TM4 proteins). Mol. Biol. Cell 7, 193-207. doi: $10.1091 / \mathrm{mbc} .7 .2 .193$

Bergin, D. A., Greene, C. M., Sterchi, E. E., Kenna, C., Geraghty, P., Belaaouaj, A., et al. (2008). Activation of the epidermal growth factor receptor (EGFR) by a novel metalloprotease pathway. J. Biol. Chem. 283, 31736-31744. doi: 10.1074/jbc.M803732200

Birchmeier, C., Birchmeier, W., Gherardi, E., and Vande Woude, G. F. (2003). Met, metastasis, motility and more. Nat. Rev. Mol. Cell Biol. 4, 915-925. doi: $10.1038 / \mathrm{nrm} 1261$

Bishop, A. L., and Hall, A. (2000). Rho GTPases and their effector proteins. Biochem. J. . 348 (Pt 2), 241-255. doi: 10.1042/bj3480241

Blaskovic, S., Blanc, M., and van der Goot, F. G. (2013). What does S-palmitoylation do to membrane proteins? FEBS J. 280, 2766-2774. doi: $10.1111 /$ febs.12263

Boavida, L. C., Qin, P., Broz, M., Becker, J. D., and McCormick, S. (2013). Arabidopsis tetraspanins are confined to discrete expression domains and cell types in reproductive tissues and form homo- and heterodimers when expressed in yeast. Plant Physiol. 163, 696-712. doi: 10.1104/pp.113.216598

Boissel, N., Leroy, H., Brethon, B., Philippe, N., de Botton, S., Auvrignon, A., et al. (2006). Incidence and prognostic impact of c-Kit, FLT3, and Ras gene mutations in core binding factor acute myeloid leukemia (CBF-AML). Leukemia 20, 965-970. doi: 10.1038/sj.leu.2404188

Bonny, M., Hui, X., Schweizer, J., Kaestner, L., Zeug, A., Kruse, K., et al. (2016). C2-domain mediated nano-cluster formation increases calcium signaling efficiency. Sci. Rep. 6:36028. doi: 10.1038/srep36028

Boots, A. W., Hristova, M., Kasahara, D. I., Haenen, G. R., Bast, A., and van der Vliet, A. (2009). ATP-mediated activation of the NADPH oxidase DUOX1 mediates airway epithelial responses to bacterial stimuli. J. Biol. Chem. 284, 17858-17867. doi: 10.1074/jbc.M809761200
Breshears, L. M., Schlievert, P. M., and Peterson, M. L. (2012). A disintegrin and metalloproteinase 17 (ADAM17) and epidermal growth factor receptor (EGFR) signaling drive the epithelial response to Staphylococcus aureus toxic shock syndrome toxin-1 (TSST-1). J. Biol. Chem. 287, 32578-32587. doi: 10.1074/jbc.M112.352534

Castagna, M., Takai, Y., Kaibuchi, K., Sano, K., Kikkawa, U., and Nishizuka, Y. (1982). Direct activation of calcium-activated, phospholipid-dependent protein kinase by tumor-promoting phorbol esters. J. Biol. Chem. 257, 7847-7851.

Charrin, S., Jouannet, S., Boucheix, C., and Rubinstein, E. (2014). Tetraspanins at a glance. J. Cell Sci. 127, 3641-3648. doi: 10.1242/jcs.154906

Charrin, S., le Naour, F., Silvie, O., Milhiet, P. E., Boucheix, C., and Rubinstein, E. (2009). Lateral organization of membrane proteins: tetraspanins spin their web. Biochem. J. 420, 133-154. doi: 10.1042/BJ20082422

Charrin, S., Manié, S., Oualid, M., Billard, M., Boucheix, C., and Rubinstein, E. (2002). Differential stability of tetraspanin/tetraspanin interactions: role of palmitoylation. FEBS Lett. 516, 139-144. doi: 10.1016/S0014-5793(02)02522-X

Chattopadhyay, N., Wang, Z., Ashman, L. K., Brady-Kalnay, S. M., and Kreidberg, J. A. (2003). alpha3beta1 integrin-CD151, a component of the cadherin-catenin complex, regulates PTPmu expression and cell-cell adhesion. J. Cell Biol. 163, 1351-1362. doi: 10.1083/jcb.200306067

Clayton, E. L., Minogue, S., and Waugh, M. G. (2013). Mammalian phosphatidylinositol 4-kinases as modulators of membrane trafficking and lipid signaling networks. Prog. Lipid Res. 52, 294-304. doi: 10.1016/j.plipres.2013.04.002

Collins, R. N. (2003). "Getting it on"-GDI displacement and small GTPase membrane recruitment. Mol. Cell 12, 1064-1066. doi: 10.1016/S1097-2765(03)00445-3

Conley, S. M., Stuck, M. W., and Naash, M. I. (2012). Structural and functional relationships between photoreceptor tetraspanins and other superfamily members. Cell. Mol. Life Sci. 69, 1035-1047. doi: 10.1007/s00018-011-0736-0

Corbacioglu, S., Kilic, M., Westhoff, M. A., Reinhardt, D., Fulda, S., and Debatin, K. M. (2006). Newly identified c-KIT receptor tyrosine kinase ITD in childhood AML induces ligand-independent growth and is responsive to a synergistic effect of imatinib and rapamycin. Blood 108, 3504-3513. doi: 10.1182/blood-2006-05-021691

Danglot, L., Chaineau, M., Dahan, M., Gendron, M. C., Boggetto, N., Perez, F., et al. (2010). Role of TI-VAMP and CD82 in EGFR cell-surface dynamics and signaling. J. Cell Sci. 123, 723-735. doi: 10.1242/jcs.062497

Delandre, C., Penabaz, T. R., Passarelli, A. L., Chapes, S. K., and Clem, R. J. (2009). Mutation of juxtamembrane cysteines in the tetraspanin CD81 affects palmitoylation and alters interaction with other proteins at the cell surface. Exp. Cell Res. 315, 1953-1963. doi: 10.1016/j.yexcr.2009.03.013

de Winde, C. M., Zuidscherwoude, M., Vasaturo, A., van der Schaaf, A., Figdor, C. G., and van Spriel, A. B. (2015). Multispectral imaging reveals the tissue distribution of tetraspanins in human lymphoid organs. Histochem. Cell Biol. 144, 133-146. doi: 10.1007/s00418-015-1326-2

Dornier, E., Coumailleau, F., Ottavi, J. F., Moretti, J., Boucheix, C., Mauduit, P., et al. (2012). TspanC8 tetraspanins regulate ADAM10/Kuzbanian trafficking and promote Notch activation in flies and mammals. J. Cell Biol. 199, 481-496. doi: $10.1083 /$ jcb. 201201133

Eisenberg, S., Laude, A. J., Beckett, A. J., Mageean, C. J., Aran, V., Hernandez-Valladares, M., et al. (2013). The role of palmitoylation in regulating Ras localization and function. Biochem. Soc. Trans. 41, 79-83. doi: $10.1042 /$ BST20120268

Fan, H., and Derynck, R. (1999). Ectodomain shedding of TGF-alpha and other transmembrane proteins is induced by receptor tyrosine kinase activation and MAP kinase signaling cascades. EMBO J. 18, 6962-6972. doi: $10.1093 / \mathrm{emboj} / 18.24 .6962$

Ford, D. A., Horner, C. C., and Gross, R. W. (1998). Protein kinase C acylation by palmitoyl coenzyme A facilitates its translocation to membranes. Biochemistry 37, 11953-11961. doi: 10.1021/bi980565w

Franco, M., Muratori, C., Corso, S., Tenaglia, E., Bertotti, A., Capparuccia, L., et al. (2010). The tetraspanin CD151 is required for Met-dependent signaling and tumor cell growth. J. Biol. Chem. 285, 38756-38764. doi: 10.1074/jbc.M110.145417

García-Frigola, C., Burgaya, F., de Lecea, L., and Soriano, E. (2001). Pattern of expression of the tetraspanin Tspan-5 during brain development in the mouse. Mech. Dev. 106, 207-212. doi: 10.1016/S0925-4773(01)00436-1 
Goemans, B. F., Zwaan, C. M., Miller, M., Zimmermann, M., Harlow, A., Meshinchi, S., et al. (2005). Mutations in KIT and RAS are frequent events in pediatric core-binding factor acute myeloid leukemia. Leukemia 19, 1536-1542. doi: 10.1038/sj.leu.2403870

Gustafson-Wagner, E., and Stipp, C. S. (2013). The CD9/CD81 tetraspanin complex and tetraspanin CD151 regulate alpha3betal integrin-dependent tumor cell behaviors by overlapping but distinct mechanisms. PLoS ONE 8:e61834. doi: 10.1371/journal.pone.0061834

Haining, E. J., Yang, J., Bailey, R. L., Khan, K., Collier, R., Tsai, S., et al. (2012). The TspanC8 subgroup of tetraspanins interacts with A disintegrin and metalloprotease 10 (ADAM10) and regulates its maturation and cell surface expression. J. Biol. Chem. 287, 39753-39765. doi: 10.1074/jbc.M112.416503

Halova, I., and Draber, P. (2016). Tetraspanins and transmembrane adaptor proteins as plasma membrane organizers-mast cell case. Front. Cell Dev. Biol. 4:43. doi: $10.3389 /$ fcell.2016.00043

Han, J., Reddig, K., and Li, H. S. (2007). Prolonged G(q) activity triggers fly rhodopsin endocytosis and degradation, and reduces photoreceptor sensitivity. EMBO J. 26, 4966-4973. doi: 10.1038/sj.emboj.7601929

Han, S. Y., Lee, M., Hong, Y. K., Hwang, S., Choi, G., Suh, Y. S., et al. (2012). Tsp66E, the Drosophila KAI1 homologue, and Tsp74F function to regulate ovarian follicle cell and wing development by stabilizing integrin localization. FEBS Lett. 586, 4031-4037. doi: 10.1016/j.febslet.2012.09.044

He, B., Liu, L., Cook, G. A., Grgurevich, S., Jennings, L. K., and Zhang, X. A. (2005). Tetraspanin CD82 attenuates cellular morphogenesis through down-regulating integrin alpha6-mediated cell adhesion. J. Biol. Chem. 280, 3346-3354. doi: 10.1074/jbc.M406680200

Hemler, M. E. (2005). Tetraspanin functions and associated microdomains. Nat. Rev. Mol. Cell Biol. 6, 801-811. doi: 10.1038/nrm1736

Hemler, M. E. (2013). Tetraspanin proteins promote multiple cancer stages. Nat. Rev. Cancer 14, 49-60. doi: 10.1038/nrc3640

Herr, M. J., Mabry, S. E., and Jennings, L. K. (2014). Tetraspanin CD9 regulates cell contraction and actin arrangement via RhoA in human vascular smooth muscle cells. PLoS ONE 9:e106999. doi: 10.1371/journal.pone.0106999

Hinkle, C. L., Mohan, M. J., Lin, P., Yeung, N., Rasmussen, F., Milla, M. E., et al. (2003). Multiple metalloproteinases process protransforming growth factoralpha (proTGF-alpha). Biochemistry 42, 127-2136. doi: 10.1021/bi026709v

Hong, I. K., Jeoung, D. I., Ha, K. S., Kim, Y. M., and Lee, H. (2012). Tetraspanin CD151 stimulates adhesion-dependent activation of Ras, Rac, and Cdc42 by facilitating molecular association between betal integrins and small GTPases. J. Biol. Chem. 287, 32027-32039. doi: 10.1074/jbc.M111.314443

Huang, S., Yuan, S., Dong, M., Su, J., Yu, C., Shen, Y., et al. (2005). The phylogenetic analysis of tetraspanins projects the evolution of cell-cell interactions from unicellular to multicellular organisms. Genomics 86, 674-684. doi: 10.1016/j.ygeno.2005.08.004

Humphries, J. D., Byron, A., and Humphries, M. J. (2006). Integrin ligands at a glance. J. Cell Sci. 119, 3901-3903. doi: 10.1242/jcs.03098

Ikeda, H., Kanakura, Y., Tamaki, T., Kuriu, A., Kitayama, H., Ishikawa, J., et al. (1991). Expression and functional role of the proto-oncogene c-kit in acute myeloblastic leukemia cells. Blood 78, 2962-2968.

Imhof, I., Gasper, W. J., and Derynck, R. (2008). Association of tetraspanin CD9 with transmembrane TGF\{alpha\} confers alterations in cell-surface presentation of TGF\{alpha\} and cytoskeletal organization. J. Cell Sci. 121, 2265-2274. doi: 10.1242/jcs.021717

Iwasaki, T., Takeda, Y., Maruyama, K., Yokosaki, Y., Tsujino, K., Tetsumoto, S., et al. (2013). Deletion of tetraspanin CD9 diminishes lymphangiogenesis in vivo and in vitro. J. Biol. Chem. 288, 2118-2131. doi: 10.1074/jbc.M112.424291

Jarikji, Z., Horb, L. D., Shariff, F., Mandato, C. A., Cho, K. W., and Horb, M. E. (2009). The tetraspanin Tm4sf3 is localized to the ventral pancreas and regulates fusion of the dorsal and ventral pancreatic buds. Development 136, 1791-1800. doi: 10.1242/dev.032235

Joazeiro, C. A., Wing, S. S., Huang, H., Leverson, J. D., Hunter, T., and Liu, Y. C. (1999). The tyrosine kinase negative regulator c-Cbl as a RING-type, E2-dependent ubiquitin-protein ligase. Science 286, 309-312. doi: 10.1126/science.286.5438.309

Jun, J. E., Rubio, I., and Roose, J. P. (2013). Regulation of ras exchange factors and cellular localization of ras activation by lipid messengers in T cells. Front. Immunol. 4:239. doi: 10.3389/fimmu.2013.00239

Jung, O., Choi, S., Jang, S. B., Lee, S. A., Lim, S. T., Choi, Y. J., et al. (2012). Tetraspan TM4SF5-dependent direct activation of FAK and metastatic potential of hepatocarcinoma cells. J. Cell Sci. 125, 5960-5973. doi: $10.1242 /$ jcs. 100586

Jura, N., Endres, N. F., Engel, K., Deindl, S., Das, R., Lamers, M. H., et al. (2009). Mechanism for activation of the EGF receptor catalytic domain by the juxtamembrane segment. Cell 137, 1293-1307. doi: 10.1016/j.cell.2009.04.025

Kaji, K., Oda, S., Miyazaki, S., and Kudo, A. (2002). Infertility of CD9-deficient mouse eggs is reversed by mouse CD9, human CD9, or mouse CD81; polyadenylated mRNA injection developed for molecular analysis of sperm-egg fusion. Dev. Biol. 247, 327-334. doi: 10.1006/dbio.2002.0694

Kaji, K., Oda, S., Shikano, T., Ohnuki, T., Uematsu, Y., Sakagami, J., et al. (2000). The gamete fusion process is defective in eggs of Cd9-deficient mice. Nat. Genet. 24, 279-282. doi: 10.1038/73502

Kang, J.-H. (2014). Protein kinase C (PKC) isozymes and cancer. N. J. Sci. 2014:36. doi: $10.1155 / 2014 / 231418$

Kedzierski, W., Bok, D., and Travis, G. H. (1999). Transgenic analysis of rds/peripherin N-glycosylation: effect on dimerization, interaction with rom1, and rescue of the rds null phenotype. J. Neurochem. 72, 430-438. doi: 10.1046/j.1471-4159.1999.0720430.x

Kenny, P. A., and Bissell, M. J. (2007). Targeting TACE-dependent EGFR ligand shedding in breast cancer. J. Clin. Invest. 117, 337-345. doi: 10.1172/JCI29518

Kitadokoro, K., Bordo, D., Galli, G., Petracca, R., Falugi, F., Abrignani, S., et al. (2001). CD81 extracellular domain 3D structure: insight into the tetraspanin superfamily structural motifs. EMBO J. 20, 12-18. doi: 10.1093/emboj/20.1.12

Kobilka, B. K. (2007). G protein coupled receptor structure and activation. Biochim. Biophys. Acta 1768, 794-807. doi: 10.1016/j.bbamem.2006.10.021

Le Naour, F., Rubinstein, E., Jasmin, C., Prenant, M., and Boucheix, C. (2000). Severely reduced female fertility in CD9-deficient mice. Science 287, 319-321. doi: $10.1126 /$ science.287.5451.319

Lennartsson, J., and Rönnstrand, L. (2012). Stem cell factor receptor/c-Kit: from basic science to clinical implications. Physiol. Rev. 92, 1619-1649. doi: 10.1152/physrev.00046.2011

Levy, S., Nguyen, V. Q., Andria, M. L., and Takahashi, S. (1991). Structure and membrane topology of TAPA-1. J. Biol. Chem. 266, 14597-14602.

Levy, S., and Shoham, T. (2005). The tetraspanin web modulates immunesignalling complexes. Nat. Rev. Immunol. 5, 136-148. doi: 10.1038/nri1548

Li, Q., Yang, X. H., Xu, F., Sharma, C., Wang, H. X., Knoblich, K., et al. (2013). Tetraspanin CD151 plays a key role in skin squamous cell carcinoma. Oncogene 32, 1772-1783. doi: 10.1038/onc.2012.205

Li, Y., Huang, X., Zhang, J., Li, Y., and Ma, K. (2013). Synergistic inhibition of cell migration by tetraspanin CD82 and gangliosides occurs via the EGFR or cMetactivated Pl3K/Akt signalling pathway. Int. J. Biochem. Cell Biol. 45, 2349-2358. doi: 10.1016/j.biocel.2013.08.002

Lineberry, N., Su, L., Soares, L., and Fathman, C. G. (2008). The single subunit transmembrane E3 ligase gene related to anergy in lymphocytes (GRAIL) captures and then ubiquitinates transmembrane proteins across the cell membrane. J. Biol. Chem. 283, 28497-28505. doi: 10.1074/jbc.M805092200

Little, K. D., Hemler, M. E., and Stipp, C. S. (2004). Dynamic regulation of a GPCR-tetraspanin-G protein complex on intact cells: central role of CD81 in facilitating GPR56-Galpha q/11 association. Mol. Biol. Cell 15, 2375-2387. doi: $10.1091 / \mathrm{mbc}$.E03-12-0886

Liu, W. M., Zhang, F., Moshiach, S., Zhou, B., Huang, C., Srinivasan, K., et al. (2012). Tetraspanin CD82 inhibits protrusion and retraction in cell movement by attenuating the plasma membrane-dependent actin organization. PLoS ONE 7:e51797. doi: 10.1371/journal.pone.0051797

Liu, X., Kapoor, T. M., Chen, J. K., and Huse, M. (2013). Diacylglycerol promotes centrosome polarization in $\mathrm{T}$ cells via reciprocal localization of dynein and myosin II. Proc. Natl. Acad. Sci. U.S.A. 110, 11976-11981. doi: 10.1073/pnas.1306180110

Liu, Z., Tian, F., Feng, X., He, Y., Jiang, P., Li, J., et al. (2013). LPS increases MUC5AC by TACE/TGF-alpha/EGFR pathway in human intrahepatic biliary epithelial cell. Biomed. Res. Int. 2013:165715. doi: 10.1155/2013/165715

Maecker, H. T., Todd, S. C., and Levy, S. (1997). The tetraspanin superfamily: molecular facilitators. FASEB J. 11, 428-442.

Mannion, B. A., Berditchevski, F., Kraeft, S. K., Chen, L. B., and Hemler, M. E. (1996). Transmembrane-4 superfamily proteins CD81 (TAPA-1), CD82, CD63, and CD53 specifically associated with integrin alpha 4 beta 1 (CD49d/CD29). J. Immunol. 157, 2039-2047.

Marjon, K. D., Termini, C. M., Karlen, K. L., Saito-Reis, C., Soria, C. E., Lidke, K. A., et al. (2016). Tetraspanin CD82 regulates bone marrow homing of acute 
myeloid leukemia by modulating the molecular organization of $\mathrm{N}$-cadherin. Oncogene 35, 4132-4140. doi: 10.1038/onc.2015.449

Matthews, A. L., Noy, P. J., Reyat, J. S., and Tomlinson, M. G. (2016). Regulation of A disintegrin and metalloproteinase (ADAM) family sheddases ADAM10 and ADAM17: The emerging role of tetraspanins and rhomboids. Platelets. doi: 10.1080/09537104.2016.1184751

Mazurov, D., Heidecker, G., and Derse, D. (2007). The inner loop of tetraspanins CD82 and CD81 mediates interactions with human T cell lymphotrophic virus type 1 Gag protein. J. Biol. Chem. 282, 3896-3903. doi: 10.1074/jbc.M607322200

Metzelaar, M. J., Wijngaard, P. L., Peters, P. J., Sixma, J. J., Nieuwenhuis, H. K., and Clevers, H. C. (1991). CD63 antigen. A novel lysosomal membrane glycoprotein, cloned by a screening procedure for intracellular antigens in eukaryotic cells. J. Biol. Chem. 266, 3239-3245.

Minder, P., Bayha, E., Becker-Pauly, C., and Sterchi, E. E. (2012). Meprinalpha transactivates the epidermal growth factor receptor (EGFR) via ligand shedding, thereby enhancing colorectal cancer cell proliferation and migration. J. Biol. Chem. 287, 35201-35211. doi: 10.1074/jbc.M112.368910

Miyado, K., Yamada, G., Yamada, S., Hasuwa, H., Nakamura, Y., Ryu, F., et al. (2000). Requirement of CD9 on the egg plasma membrane for fertilization. Science 287, 321-324. doi: 10.1126/science.287.5451.321

Mochizuki, S., and Okada, Y. (2007). ADAMs in cancer cell proliferation and progression. Cancer Sci. 98, 621-628. doi: 10.1111/j.1349-7006.2007.00434.x

Moral, Z., Dong, K., Wei, Y., Sterling, H., Deng, H., Ali, S., et al. (2001). Regulation of ROMK1 channels by protein-tyrosine kinase and -tyrosine phosphatase. J. Biol. Chem. 276, 7156-7163. doi: 10.1074/jbc.M008671200

Murayama, Y., Shinomura, Y., Oritani, K., Miyagawa, J., Yoshida, H., Nishida, M., et al. (2008). The tetraspanin CD9 modulates epidermal growth factor receptor signaling in cancer cells. J. Cell. Physiol. 216, 135-143. doi: 10.1002/jcp.21384

Navarro, M. N., and Cantrell, D. A. (2014). Serine-threonine kinases in TCR signaling. Nat. Immunol. 15, 808-814. doi: 10.1038/ni.2941

Newton, A. C. (1995). Protein kinase C: structure, function, and regulation. J. Biol. Chem. 270, 28495-28498. doi: 10.1074/jbc.270.48.28495

Novitskaya, V., Romanska, H., Kordek, R., Potemski, P., Kusinska, R., Parsons, M., et al. (2014). Integrin alpha3beta1-CD151 complex regulates dimerization of ErbB2 via RhoA. Oncogene 33, 2779-2789. doi: 10.1038/onc.2013.231

Odintsova, E., Butters, T. D., Monti, E., Sprong, H., van Meer, G., and Berditchevski, F. (2006). Gangliosides play an important role in the organization of CD82-enriched microdomains. Biochem. J. 400, 315-325. doi: 10.1042/BJ20060259

Odintsova, E., Sugiura, T., and Berditchevski, F. (2000). Attenuation of EGF receptor signaling by a metastasis suppressor, the tetraspanin CD82/KAI-1. Curr. Biol. 10, 1009-1012. doi: 10.1016/S0960-9822(00)00652-7

Odintsova, E., van Niel, G., Conjeaud, H., Raposo, G., Iwamoto, R., Mekada, E., et al. (2013). Metastasis suppressor tetraspanin CD82/KAI1 regulates ubiquitylation of epidermal growth factor receptor. J. Biol. Chem. 288, 26323-26334. doi: 10.1074/jbc.M112.439380

Odintsova, E., Voortman, J., Gilbert, E., and Berditchevski, F. (2003). Tetraspanin CD82 regulates compartmentalisation and ligand-induced dimerization of EGFR. J. Cell Sci. 116, 4557-4566. doi: 10.1242/jcs.00793

Ono, M., Handa, K., Withers, D. A., and Hakomori, S. (1999). Motility inhibition and apoptosis are induced by metastasis-suppressing gene product CD82 and its analogue CD9, with concurrent glycosylation. Cancer Res. 59, 2335-2339.

Organ, S. L., and Tsao, M. S. (2011). An overview of the c-MET signaling pathway. Ther. Adv. Med. Oncol. 3, S7-S19.

Pandiella, A., and Massagué, J. (1991). Cleavage of the membrane precursor for transforming growth factor alpha is a regulated process. Proc. Natl. Acad. Sci. U.S.A. 88, 1726-1730. doi: 10.1073/pnas.88.5.1726

Paschka, P., Marcucci, G., Ruppert, A. S., Mrózek, K., Chen, H., Kittles, R. A., et al. (2006). Adverse prognostic significance of KIT mutations in adult acute myeloid leukemia with $\operatorname{inv}(16)$ and $\mathrm{t}(8 ; 21)$ : a cancer and leukemia group B study. J. Clin. Oncol. 24, 3904-3911. doi: 10.1200/JCO.2006.06.9500

Peschon, J. J., Slack, J. L., Reddy, P., Stocking, K. L., Sunnarborg, S. W., Lee, D. C., et al. (1998). An essential role for ectodomain shedding in mammalian development. Science 282, 1281-1284. doi: 10.1126/science.282.5392.1281

Prox, J., Willenbrock, M., Weber, S., Lehmann, T., Schmidt-Arras, D., Schwanbeck, R., et al. (2012). Tetraspanin 15 regulates cellular trafficking and activity of the ectodomain sheddase ADAM10. Cell. Mol. Life Sci. 69, 2919-2932. doi: 10.1007/s00018-012-0960-2
Rocha-Perugini, V., González-Granado, J. M., Tejera, E., López-Martín, S., YañezMó, M., and Sánchez-Madrid, F. (2014). Tetraspanins CD9 and CD151 at the immune synapse support T-cell integrin signaling. Eur. J. Immunol. 44, 1967-1975. doi: 10.1002/eji.201344235

Rubinstein, E., Le Naour, F., Billard, M., Prenant, M., and Boucheix, C. (1994). CD9 antigen is an accessory subunit of the VLA integrin complexes. Eur. J. Immunol. 24, 3005-3013. doi: 10.1002/eji.1830241213

Ruiz-García, A., López-López, S., García-Ramìrez, J. J., Baladrón, V., Ruiz-Hidalgo, M. J., López-Sanz, L., et al. (2016). The tetraspanin TSPAN33 controls TLRTriggered macrophage activation through modulation of NOTCH signaling. J. Immunol. 197, 3371-3381. doi: 10.4049/jimmunol.1600421

Ryan, P. E., Davies, G. C., Nau, M. M., and Lipkowitz, S. (2006). Regulating the regulator: negative regulation of $\mathrm{Cbl}$ ubiquitin ligases. Trends Biochem. Sci. 31, 79-88. doi: 10.1016/j.tibs.2005.12.004

Sadej, R., Romanska, H., Kavanagh, D., Baldwin, G., Takahashi, T., Kalia, N., et al. (2010). Tetraspanin CD151 regulates transforming growth factor beta signaling: implication in tumor metastasis. Cancer Res. 70, 6059-6070. doi: 10.1158/0008-5472.CAN-09-3497

Schlaepfer, D. D., Hauck, C. R., and Sieg, D. J. (1999). Signaling through focal adhesion kinase. Prog. Biophys. Mol. Biol. 71, 435-478. doi: $10.1016 /$ S0079-6107(98)00052-2

Schlessinger, J., and Ullrich, A. (1992). Growth factor signaling by receptor tyrosine kinases. Neuron 9, 383-391. doi: 10.1016/0896-6273(92)90177-F

Schwartz, M. A. (2001). Integrin signaling revisited. Trends Cell Biol. 11, 466-470. doi: $10.1016 /$ S0962-8924(01)02152-3

Seals, D. F., and Courtneidge, S. A. (2003). The ADAMs family of metalloproteases: multidomain proteins with multiple functions. Genes Dev. 17, 7-30. doi: $10.1101 /$ gad.1039703

Seigneuret, M. (2006). Complete predicted three-dimensional structure of the facilitator transmembrane protein and hepatitis C virus receptor CD81: conserved and variable structural domains in the tetraspanin superfamily. Biophys. J. 90, 212-227. doi: 10.1529/biophysj.105.069666

Seigneuret, M., Delaguillaumie, A., Lagaudriére-Gesbert, C., and Conjeaud, H. (2001). Structure of the tetraspanin main extracellular domain. A partially conserved fold with a structurally variable domain insertion. J. Biol. Chem. 276, 40055-40064. doi: 10.1074/jbc.M105557200

Seubert, B., Cui, H., Simonavicius, N., Honert, K., Schäfer, S., Reuning, U., et al. (2015). Tetraspanin CD63 acts as a pro-metastatic factor via beta-catenin stabilization. Int. J. Cancer 136, 2304-2315. doi: 10.1002/ijc.29296

Shi, W., Fan, H., Shum, L., and Derynck, R. (2000). The tetraspanin CD9 associates with transmembrane TGF-alpha and regulates TGF-alpha-induced EGF receptor activation and cell proliferation. J. Cell Biol. 148, 591-602. doi: $10.1083 /$ jcb.148.3.591

Shigeta, M., Sanzen, N., Ozawa, M., Gu, J., Hasegawa, H., and Sekiguchi, K. (2003). CD151 regulates epithelial cell-cell adhesion through PKC- and Cdc42-dependent actin cytoskeletal reorganization. J. Cell Biol. 163, 165-176. doi: $10.1083 /$ jcb. 200301075

Singh, B., and Coffey, R. J. (2014). From wavy hair to naked proteins: the role of transforming growth factor alpha in health and disease. Semin. Cell Dev. Biol. 28, 12-21. doi: 10.1016/j.semcdb.2014.03.003

Sit, S. T., and Manser, E. (2011). Rho GTPases and their role in organizing the actin cytoskeleton. J. Cell Sci. 124, 679-683. doi: 10.1242/jcs.064964

Slupsky, J. R., Seehafer, J. G., Tang, S. C., Masellis-Smith, A., and Shaw, A. R. (1989). Evidence that monoclonal antibodies against CD9 antigen induce specific association between CD9 and the platelet glycoprotein IIb-IIIa complex. J. Biol. Chem. 264, 12289-12293.

Sridhar, S. C., and Miranti, C. K. (2006). Tetraspanin KAI1/CD82 suppresses invasion by inhibiting integrin-dependent crosstalk with c-Met receptor and Src kinases. Oncogene 25, 2367-2378. doi: 10.1038/sj.onc.1209269

Stawowy, P., Margeta, C., Blaschke, F., Lindschau, C., Spencer-Hänsch, C., Leitges, M., et al. (2005). Protein kinase C epsilon mediates angiotensin II-induced activation of betal-integrins in cardiac fibroblasts. Cardiovasc. Res. 67, 50-59. doi: 10.1016/j.cardiores.2005.03.002

Stipp, C. S. (2010). Laminin-binding integrins and their tetraspanin partners as potential antimetastatic targets. Expert Rev. Mol. Med. 12:e3. doi: $10.1017 /$ S1462399409001355

Stipp, C. S., and Hemler, M. E. (2000). Transmembrane-4-superfamily proteins CD151 and CD81 associate with alpha 3 beta 1 integrin, and selectively 
contribute to alpha 3 beta 1-dependent neurite outgrowth. J. Cell Sci. 113 (Pt 11), 1871-11882.

Stipp, C. S., Orlicky, D., and Hemler, M. E. (2001). FPRP, a major, highly stoichiometric, highly specific CD81- and CD9-associated protein. J. Biol. Chem. 276, 4853-4862. doi: 10.1074/jbc.M009859200

Stuck, M. W., Conley, S. M., and Naash, M. I. (2012). Defects in the outer limiting membrane are associated with rosette development in the Nrl-/- retina. PLoS ONE 7:e32484. doi: 10.1371/journal.pone.0032484

Stuck, M. W., Conley, S. M., and Naash, M. I. (2015). Retinal Degeneration Slow (RDS) glycosylation plays a role in cone function and in the regulation of RDS. ROM-1 protein complex formation. J. Biol. Chem. 290, 27901-27913. doi: 10.1074/jbc.M115.683698

Sulzmaier, F. J., Jean, C., and Schlaepfer, D. D. (2014). FAK in cancer: mechanistic findings and clinical applications. Nat. Rev. Cancer 14, 98-610. doi: $10.1038 / \mathrm{nrc} 3792$

Takahashi, M., Sugiura, T., Abe, M., Ishii, K., and Shirasuna, K. (2007). Regulation of c-Met signaling by the tetraspanin KAI-1/CD82 affects cancer cell migration. Int. J. Cancer 121, 1919-1929. doi: 10.1002/ijc.22887

Tejera, E., Rocha-Perugini, V., López-Martin, S., Perez-Hernández, D., Bachir, A. I., Horwitz, A. R., et al. (2013). CD81 regulates cell migration through its association with Rac GTPase. Mol. Biol. Cell 24, 261-273. doi: 10.1091/mbc.E12-09-0642

Termini, C. M., Cotter, M. L., Marjon, K. D., Buranda, T., Lidke, K. A., and Gillette, J. M. (2014). The membrane scaffold CD82 regulates cell adhesion by altering alpha4 integrin stability and molecular density. Mol. Biol. Cell 25, 1560-1573. doi: 10.1091/mbc.E13-11-0660

Termini, C. M., Lidke, K. A., and Gillette, J. M. (2016). Tetraspanin CD82 regulates the spatiotemporal dynamics of PKCalpha in acute myeloid leukemia. Sci. Rep. 6:29859. doi: 10.1038/srep29859

Thorne, B. A., and Plowman, G. D. (1994). The heparin-binding domain of amphiregulin necessitates the precursor pro-region for growth factor secretion. Mol. Cell. Biol. 14, 1635-1646. doi: 10.1128/MCB.14.3.1635

Tomas, A., Futter, C. E., and Eden, E. R. (2014). EGF receptor trafficking: consequences for signaling and cancer. Trends Cell Biol. 24, 26-34. doi: 10.1016/j.tcb.2013.11.002

Tomlinson, M. G., Williams, A. F., and Wright, M. D. (1993). Epitope mapping of anti-rat CD53 monoclonal antibodies. Implications for the membrane orientation of the Transmembrane 4 Superfamily. Eur. J. Immunol. 23, 136-140.

Tsai, F. D., and Philips, M. R. (2012). Rac1 gets fattier. EMBO J. 31, 517-518. doi: 10.1038/emboj.2011.481

Tsukamoto, S., Takeuchi, M., Kawaguchi, T., Togasaki, E., Yamazaki, A., Sugita, Y., et al. (2014). Tetraspanin CD9 modulates ADAM17-mediated shedding of LR11 in leukocytes. Exp. Mol. Med. 46:e89. doi: 10.1038/emm.2013.161

Tuteja, N. (2009). Signaling through G protein coupled receptors. Plant Signal. Behav. 4, 942-947. doi: 10.4161/psb.4.10.9530

Valenta, T., Hausmann, G., and Basler, K. (2012). The many faces and functions of beta-catenin. EMBO J. 31, 2714-2736. doi: 10.1038/emboj.2012.150

Valley, C. C., Liu, S., Lidke, D. S., and Lidke, K. A. (2015). Sequential superresolution imaging of multiple targets using a single fluorophore. PLoS ONE 10:e0123941. doi: 10.1371/journal.pone.012394

van Spriel, A. B. (2011). Tetraspanins in the humoral immune response. Biochem. Soc. Trans. 39, 512-517. doi: 10.1042/BST0390512

van Spriel, A. B., de Keijzer, S., van der Schaaf, A., Gartlan, K. H., Sofi, M., Light, A., et al. (2012). The tetraspanin CD37 orchestrates the $\alpha(4) \beta(1)$ integrin-Akt signaling axis and supports long-lived plasma cell survival. Sci. Signal. 5:ra82. doi: $10.1126 /$ scisignal.2003113

Waldron, R. T., Rey, O., Iglesias, T., Tugal, T., Cantrell, D., and Rozengurt, E. (2001). Activation loop Ser744 and Ser748 in protein kinase D are transphosphorylated in vivo. J. Biol. Chem. 276, 32606-32615. doi: 10.1074/jbc.M101648200

Wang, H., Zhang, W., Zhao, J., Zhang, L., Liu, M., Yan, G., et al. (2012). N-Glycosylation pattern of recombinant human CD82 (KAI1), a tumor-associated membrane protein. J. Proteomics 75, 1375-1385. doi: 10.1016/j.jprot.2011.11.013

Wang, Y., Tong, X., Omoregie, E. S., Liu, W., Meng, S., and Ye, X. (2012). Tetraspanin 6 (TSPAN6) negatively regulates retinoic acid-inducible gene I-like receptor-mediated immune signaling in a ubiquitination-dependent manner. J. Biol. Chem. 287, 34626-34634. doi: 10.1074/jbc.M112.390401
Winterwood, N. E., Varzavand, A., Meland, M. N., Ashman, L. K., and Stipp, C. S. (2006). A critical role for tetraspanin CD151 in alpha3beta1 and alpha6beta4 integrin-dependent tumor cell functions on laminin-5. Mol. Biol. Cell 17, 2707-2721. doi: 10.1091/mbc.E05-11-1042

Wright, M. D., Ni, J., and Rudy, G. B. (2000). The L6 membrane proteinsa new four-transmembrane superfamily. Protein Sci. 9, 1594-1600. doi: $10.1110 /$ ps.9.8.1594

Xu, D., Sharma, C., and Hemler, M. E. (2009). Tetraspanin 12 regulates ADAM10dependent cleavage of amyloid precursor protein. FASEB J. 23, 674-3681. doi: 10.1096/fj.09-133462

Xu, H., Lee, S. J., Suzuki, E., Dugan, K. D., Stoddard, A., Li, H. S., et al. (2004). A lysosomal tetraspanin associated with retinal degeneration identified via a genome-wide screen. EMBO J. 23, 811-822. doi: 10.1038/sj.emboj.7600112

$\mathrm{Xu}$, L., and Hynes, R. O. (2007). GPR56 and TG2: possible roles in suppression of tumor growth by the microenvironment. Cell Cycle 6, 160-165. doi: $10.4161 /$ cc.6.2.3760

Yamada, M., Sumida, Y., Fujibayashi, A., Fukaguchi, K., Sanzen, N., Nishiuchi, R., et al. (2008). The tetraspanin CD151 regulates cell morphology and intracellular signaling on laminin-511. FEBS J. 275, 3335-3351. doi: 10.1111/j.1742-4658.2008.06481.x

Yáñez-Mo, M., Alfranca, A., Cabañas, C., Marazuela, M., Tejedor, R., Ursa, M. A., et al. (1998). Regulation of endothelial cell motility by complexes of tetraspan molecules CD81/TAPA-1 and CD151/PETA-3 with alpha3 beta1 integrin localized at endothelial lateral junctions. J. Cell Biol. 141, 791-804. doi: $10.1083 /$ jcb.141.3.791

Yáñez-Mo, M., Sánchez-Madrid, F., and Cabanas, C. (2011). Membrane proteases and tetraspanins. Biochem. Soc. Trans. 39, 541-546. doi: 10.1042/BST0390541

Yáñez-Mo, M., Tejedor, R., Rousselle, P., and Sanchez -Madrid, F. (2001). Tetraspanins in intercellular adhesion of polarized epithelial cells: spatial and functional relationship to integrins and cadherins. J. Cell Sci. 114, 577-587.

Yang, X., Claas, C., Kraeft, S. K., Chen, L. B., Wang, Z., Kreidberg, J. A., et al. (2002). Palmitoylation of tetraspanin proteins: modulation of CD151 lateral interactions, subcellular distribution, and integrin-dependent cell morphology. Mol. Biol. Cell. 13, 767-781. doi: 10.1091/mbc.01-05-0275

Yang, X., Kovalenko, O. V., Tang, W., Claas, C., Stipp, C. S., and Hemler, M. E. (2004). Palmitoylation supports assembly and function of integrin-tetraspanin complexes. J. Cell Biol. 167, 1231-1240. doi: 10.1083/jcb.200404100

Yauch, R. L., Felsenfeld, D. P., Kraeft, S. K., Chen, L. B., Sheetz, M. P., and Hemler, M. E. (1997). Mutational evidence for control of cell adhesion through integrin diffusion/clustering, independent of ligand binding. J. Exp. Med. 186, 1347-1355. doi: 10.1084/jem.186.8.1347

Yauch, R. L., and Hemler, M. E. (2000). Specific interactions among transmembrane 4 superfamily (TM4SF) proteins and phosphoinositide 4-kinase. Biochem. J. 351(Pt 3), 629-637. doi: 10.1042/bj3510629

Zhang, F., Michaelson, J. E., Moshiach, S., Sachs, N., Zhao, W., Sun, Y., et al. (2011). Tetraspanin CD151 maintains vascular stability by balancing the forces of cell adhesion and cytoskeletal tension. Blood 118, 4274-4284. doi: 10.1182/blood-2011-03-339531

Zhang, X. A., Bontrager, A. L., and Hemler, M. E. (2001). Transmembrane4 superfamily proteins associate with activated protein kinase $\mathrm{C}$ (PKC) and link PKC to specific beta(1) integrins. J. Biol. Chem. 276, 25005-25013. doi: 10.1074/jbc.M102156200

Zimmerman, B., Kelly, B., McMillan, B. J., Seegar, T. C., Dror, R. O., Kruse, A. C., et al. (2016). Crystal structure of a full-length human tetraspanin reveals a cholesterol-binding pocket. Cell 167, 1041.e11-1051.e11. doi: 10.1016/j.cell.2016.09.056

Zoller, M. (2009). Tetraspanins: push and pull in suppressing and promoting metastasis. Nat. Rev. Cancer 9, 40-55. doi: 10.1038/nrc2543

Conflict of Interest Statement: The authors declare that the research was conducted in the absence of any commercial or financial relationships that could be construed as a potential conflict of interest.

Copyright (C) 2017 Termini and Gillette. This is an open-access article distributed under the terms of the Creative Commons Attribution License (CC BY). The use, distribution or reproduction in other forums is permitted, provided the original author(s) or licensor are credited and that the original publication in this journal is cited, in accordance with accepted academic practice. No use, distribution or reproduction is permitted which does not comply with these terms. 